\title{
PTEN activation contributes to neuronal and synaptic engulfment by microglia in tauopathy
}

\author{
Joseph Benetatos ${ }^{1} \cdot$ Rachel E. Bennett ${ }^{2}$ Harrison T. Evans ${ }^{1} \cdot$ Sevannah A. Ellis ${ }^{1} \cdot$ Bradley T. Hyman $^{2}$. \\ Liviu-Gabriel Bodea ${ }^{1}$ (1) J Jürgen Götz ${ }^{1}$
}

Received: 1 November 2019 / Revised: 16 March 2020 / Accepted: 17 March 2020 / Published online: 31 March 2020

(c) The Author(s) 2020

\begin{abstract}
Phosphatase and tensin homolog (PTEN) regulates synaptic density in development; however, whether PTEN also regulates synapse loss in a neurodegenerative disorder such as frontotemporal lobar degeneration with Tau deposition (FTLD-Tau) has not been explored. Here, we found that pathological Tau promotes early activation of PTEN, which precedes apoptotic caspase-3 cleavage in the rTg4510 mouse model of FTLD-Tau. We further demonstrate increased synaptic and neuronal exposure of the apoptotic signal phosphatidylserine that tags neuronal structures for microglial uptake, thereby linking PTEN activation to synaptic and neuronal structure elimination. By applying pharmacological inhibition of PTEN's protein phosphatase activity, we observed that microglial uptake can be decreased in Tau transgenic mice. Finally, we reveal a dichotomous relationship between PTEN activation and age in FTLD-Tau patients and healthy controls. Together, our findings suggest that in tauopathy, PTEN has a role in the synaptotoxicity of pathological Tau and promotes microglial removal of affected neuronal structures.
\end{abstract}

Keywords Microglia $\cdot$ Neurodegeneration $\cdot$ Phagocytosis $\cdot$ PTEN $\cdot$ Synapse $\cdot$ Tau

\section{Introduction}

Synapse loss is the best cellular correlate of impaired cognitive function in primary tauopathies, such as frontotemporal lobar degeneration-Tau (FTLD-Tau), and Alzheimer's disease (AD) as the major secondary tauopathy [43, 52]. Despite this, our understanding of the process by which synapse loss occurs is limited [46]. In tauopathies, the normal axonal enrichment of Tau becomes disrupted and

Electronic supplementary material The online version of this article (https://doi.org/10.1007/s00401-020-02151-9) contains supplementary material, which is available to authorized users.

Liviu-Gabriel Bodea

1.bodea@uq.edu.au

$\triangle$ Jürgen Götz

j.goetz@uq.edu.au

1 Clem Jones Centre for Ageing Dementia Research, Queensland Brain Institute, The University of Queensland, Brisbane, QLD, Australia

2 Department of Neurology, MassGeneral Institute for Neurodegenerative Disease, Massachusetts General Hospital, Harvard Medical School, Charlestown, MA, USA pathologically phosphorylated Tau progressively accumulates in the somatodendritic compartment, including synapses [19, 31, 58].

Because there is evidence that synapse loss, including that in tauopathies, involves intracellular components of apoptosis [45], we investigated the role of the lipid and protein phosphatase PTEN in this process. PTEN has been linked to neuronal apoptosis [13] and more specifically to the homeostatic regulation of dendritic spine numbers, in that a loss of PTEN causes excessive overgrowth of spines [29], whereas its overexpression results in their dramatic loss $[40,67]$. PTEN activity is regulated by phosphorylation at serine (S) and threonine $(\mathrm{T})$ residues which are located in its carboxyterminal domain. The enzyme further presents with a PDZ-binding domain that facilitates the interaction with adaptor proteins, such as postsynaptic density protein 95 (PSD-95) [24, 28, 67].

In development, PTEN regulates neuronal density in an activity-dependent manner, and blocking PTEN in neurons with reduced activity prevents their apoptotic death [64]. Synaptic removal has further been demonstrated to involve microglial cells, both in development $[42,54]$ and in Tau and amyloid- $\beta(A \beta)$ mouse models of AD $[10,18]$. Synapse 
engulfment by microglia requires extracellular molecules that are linked to apoptosis, such as phosphatidylserine (PS) and the complement factor C1q $[16,18]$. PTEN has been shown to impair synaptic function in the APP/PSEN1 mouse model [28], but it has not been directly linked to synaptic elimination mediated by microglia. Taken together, this led us to hypothesize that synaptic and neuronal removal in disease may be mediated by a mechanism involving PTEN.

Here, we show that PTEN activation occurs early in disease pathogenesis in the rTg4510 and K3 tauopathy mouse models, whereas with advanced pathology, PTEN activation drops, similarly to what we observed in human FTLD-Tau patient brains. During the period of high PTEN activation, synapses and neuronal structures of $\mathrm{rTg} 4510$ mice increasingly expose the apoptotic signal PS, accumulate $\mathrm{C} 1 \mathrm{q}$ and are engulfed by microglia. Pharmacological inhibition of PTEN in rTg4510 mice significantly reduces synaptic phagocytosis by microglia, preventing the loss of synaptic PSD-95 as well as preserving neuronal density in the hippocampus without affecting the level or phosphorylation of Tau, thereby placing PTEN activation downstream of Tau. Together, our data present PTEN as a mediator of tauopathy by facilitating the elimination of synapses and neuronal structures by microglia.

\section{Materials and methods}

\section{Mice}

Animal experimentation was approved by the Animal Ethics Committee of the University of Queensland (UQ) (approval numbers QBI/348/17/NHMRC and QBI/554/17/NHMRC) and by the Centre for Comparative Medicine (CCM) at Massachusetts General Hospital (MGH), in accordance with the National Institutes of Health Guide for the Care and Use of Laboratory Animals. The animals were housed in specific pathogen-free cages and maintained on a $12 \mathrm{~h}$ light/ dark cycle, with constant access to food and water. Transgenic rTg4510 mice express human four-repeat Tau with the P301L mutation linked to hereditary tauopathy [41]. Male mice were used unless otherwise stated in the methods section. Mouse tissue extracts were prepared at UQ, with the exception of tissue from 15 and 18 month-old wild-type and $\mathrm{rTg} 4510$ mice which were prepared at MGH. K3 mice express the K369I mutation of Tau under the control of the mThy 1.2 promoter [21], and $\mathrm{Cx} 3 \mathrm{Cr} 1^{\mathrm{eGFP} /-}$ mice express EGFP under the control of the microglia-specific $\mathrm{Cx} 3 \mathrm{Cr} 1$ promoter [23]. For both $\mathrm{K} 3$ and $\mathrm{Cx} 3 \mathrm{Cr} 1^{\mathrm{eGFP} /-}$ strains, mice from both genders were used. APP23 mice overexpress human mutant amyloid precursor protein harboring the Swedish mutation [55].

\section{Human samples}

Autopsy tissue from FTLD-Tau and healthy-control cases from MGH were collected with informed consent of patients or their relatives and after approval of local institutional review boards has been obtained. Human patient demographic information for control and FTLD-Tau is provided in Table 1. All experimentation with human tissue was performed at MGH.

\section{Primary neuronal cultures}

Embryonic day (E) 17 cortical and hippocampal neurons were obtained from rTg4510 and non-transgenic (WT) embryos and plated onto poly-D-lysine (PDL)-coated coverslips in a 24-well plate, at a density of 30,000 cells/well. For their culture, Neurobasal medium (Gibco) was supplemented with 5\% fetal bovine serum (Hyclone), 2\% B27 (Gibco), $2 \mathrm{mM}$ Glutamax (Gibco) and 50 U/ml penicillin/ streptomycin (Invitrogen). The medium was changed to serum-free Neurobasal medium $24 \mathrm{~h}$ post-seeding and half of the medium was further changed twice a week.

\section{Primary microglial/neuronal co-culture}

Cortices were dissected from postnatal day 3 $\mathrm{Cx} 3 \mathrm{Cr} 1^{\mathrm{eGFP} /-}$ pups. Cortices were plated into flasks containing DMEM-F12 (Gibco) supplemented with $50 \mathrm{U} / \mathrm{ml}$ penicillin/streptomycin (Invitrogen), $2 \mathrm{mM}$ Glutamax (Gibco) and $0.45 \%$ glucose (Sigma). The medium was changed $24 \mathrm{~h}$ after plating and then every 5 days. Day in vitro (DIV) 21-28 microglia were isolated by placing the flasks for $3 \mathrm{~h}$ in an orbital shaker in a $37{ }^{\circ} \mathrm{C}$ incubator at $450 \mathrm{rpm}$. Supernatants were collected and filtered through a $70 \mu \mathrm{m}$ cell strainer, followed by centrifugation at $200 \mathrm{rpm}$ to obtain the microglial pellet. For replating on primary neurons, the microglial pellet was resuspended in medium supplemented with Neurobasal, adding 30,000 microglia to 30,000 neurons maintained in a 24-well plate.

For the microglial phagocytosis assay, microglia were resuspended in DMEM-F12 and plated into a PDL-coated black, clear bottom 96-well plate at a density of 10,000 microglia/well.

\section{Synaptosomal and PSD fraction preparation}

Subcellular fractionation was performed with minor modifications as described previously [35]. rTg4510 mice were deeply anesthetized with sodium pentobarbital and brains were extracted following perfusion with PBS. Brain tissue was first homogenized on ice in sucrose buffer $(0.32 \mathrm{M}$ 
Table 1 Human cases used for PTEN analysis

\begin{tabular}{|c|c|c|c|c|c|c|}
\hline \# & Diagnosis & $\begin{array}{l}\text { Chromosomal } \\
\text { abnormality }\end{array}$ & Braak & Age & Gender & $\begin{array}{l}\text { Post } \\
\text { mortem } \\
\text { interval }\end{array}$ \\
\hline 1 & Control & & II & $90+$ & $\mathrm{F}$ & 24 \\
\hline 2 & Control & & I & 68 & M & 27 \\
\hline 3 & Control & & I & 98 & M & 24 \\
\hline 4 & Control & & & 86 & M & 10 \\
\hline 5 & Control & & 0 & $90+$ & $\mathrm{m}$ & 21 \\
\hline 6 & Dementia lacking distinctive histology (DLDH) & & I & 78 & $\mathrm{~F}$ & 6 \\
\hline 7 & Control & & I & $90+$ & $\mathrm{F}$ & 8 \\
\hline 8 & Frontotemporal lobar degeneration with Tau pathology (FTLD-tau) & P301L & IV & 71 & $\mathrm{f}$ & 4 \\
\hline 9 & Frontotemporal lobar degeneration with Tau pathology (FTLD-tau) & $\mathrm{P} 301 \mathrm{~L}$ & & 56 & M & \\
\hline 10 & Corticobasal degeneration (CBD) & $\mathrm{P} 301 \mathrm{~L}$ & 0 & 61 & M & 14 \\
\hline 11 & Pick's disease type A (PiD-A) & P301L & & 70 & M & 12 \\
\hline 12 & Pick's disease (PiD) & $\mathrm{P} 301 \mathrm{~L}$ & & 33 & M & 33 \\
\hline 13 & Frontotemporal lobar degeneration (FTLD-TAU) & & 0 & 70 & M & 2 \\
\hline 14 & Frontotemporal lobar degeneration with Tau pathology (FTLD-tau) & & & 71 & $\mathrm{~F}$ & 12 \\
\hline 15 & Frontotemporal lobar degeneration with Tau pathology (FTLD-tau) & & & 70 & $\mathrm{~F}$ & 12 \\
\hline 16 & Frontotemporal lobar degeneration with Tau pathology (FTLD-tau) & & & $90+$ & $\mathrm{F}$ & \\
\hline
\end{tabular}

sucrose, $10 \mathrm{mM}$ HEPES, $\mathrm{pH}$ 7.4), and the total brain homogenate was centrifuged at $1000 \times g$ for $10 \mathrm{~min}$ at $4{ }^{\circ} \mathrm{C}$, yielding the supernatant fraction or total protein (TP) and the nuclear enriched pellet (P1). The supernatant was centrifuged at $14,000 \mathrm{~g}$ for $20 \mathrm{~min}$ at $4{ }^{\circ} \mathrm{C}$ to obtain the crude synaptosomal fraction (P2) and the cytosolic protein enriched supernatant (Cyto). The P2 pellet was washed twice with wash buffer ( 4 mM HEPES, 1 mM EDTA, pH 7.4) by resuspension and centrifugation at $12,000 \times g$ for $20 \mathrm{~min}$ at $4{ }^{\circ} \mathrm{C}$ and then resuspended in buffer A (20 mM HEPES, $100 \mathrm{mM}$ $\mathrm{NaCl}, 0.5 \%$ Triton $\mathrm{X}-100, \mathrm{pH} 7.2$ ). After rotation at $4{ }^{\circ} \mathrm{C}$ for $1 \mathrm{~h}$, the suspension was centrifuged at $12,000 \times \mathrm{g}$ for $20 \mathrm{~min}$ at $4{ }^{\circ} \mathrm{C}$ to yield the non-PSD fraction containing extra-synaptic proteins. The resultant pellet was washed twice in wash buffer and then resuspended in buffer B (20 mM HEPES, $0.15 \mathrm{mM} \mathrm{NaCl}, 1 \%$ Triton $\mathrm{X}-100,1 \%$ SDS, $1 \mathrm{mM}$ dithiothreitol, $1 \%$ deoxycholate, $\mathrm{pH} 7.5$ ) for $1 \mathrm{~h}$ at $4{ }^{\circ} \mathrm{C}$, followed by centrifugation at $10,000 \times g$ for $20 \mathrm{~min}$ at $4{ }^{\circ} \mathrm{C}$ to obtain the PSD fraction containing synaptic proteins. All buffers were freshly supplemented with protease and phosphatase inhibitor cocktail (Cell Signaling Technology) prior to use, and fractions were stored as aliquots at $-80{ }^{\circ} \mathrm{C}$.

\section{In vitro engulfment assay}

To obtain pHrodo-conjugated synaptosomes, synaptosomes purified from rTg4510 and WT brains were incubated at room temperature (RT) in isotonic buffer containing pHrodo$\mathrm{AM}^{\mathrm{TM}}$ Red succinimidyl ester (Invitrogen) under gentle agitation. After 30 min incubation, unbound pHrodo dye was washed out by multiple rounds of centrifugation, and the pHrodo-conjugated synaptosomes were resuspended in isotonic buffer containing $10 \%$ DMSO and stored at $-30{ }^{\circ} \mathrm{C}$ until use. On the day of the assay, synaptosomes were thawed and diluted in live cell imaging solution and added in triplicate to a 96-well plate, with wells either containing DIV 21-28 primary microglia obtained from $\mathrm{Cx} 3 \mathrm{Cr} 1^{\mathrm{eGFP} /-}$ mice, or no microglia. The 96-well plate was placed immediately into a fluorescence plate reader and the intensity from each well was obtained. This was repeated after $15 \mathrm{~min}$ and then again every $30 \mathrm{~min}$ for a total duration of $4.25 \mathrm{~h}$. The plotted intensity was obtained by subtracting of wells without microglia from that of wells containing microglia.

\section{Western blot analysis of mouse tissue}

Total brain and synaptosomes were solubilized in RIPA buffer supplemented with protease and phosphatase inhibitors followed by sonication, using a probe sonicator set of $20 \mathrm{~s}$ at a $20 \%$ power. Samples were centrifuged at $12 \mathrm{k} \mathrm{rpm}$ for $10 \mathrm{~min}$ at $4{ }^{\circ} \mathrm{C}$. Protein $(10-20 \mu \mathrm{g})$ from each sample was loaded onto a $4-15 \%$ Bis-Tris gels, transferred to a PVDF membrane and blocked for $1 \mathrm{~h}$ with Tris-buffered saline with Tween-20 (TBS-T) blocking buffer, and then incubated in primary antibodies at 1:1000 in TBS-T blocking buffer overnight. Then, membranes were washed $3 \times 5$ min in TBS-T. Secondary antibodies were added at 1:10,000 for $1 \mathrm{~h}$ in $50 \%$ TBS-T blocking buffer. A Li-Cor detection system was used for imaging. For reprobing, blots were stripped using Reblot 
plus strong antibody stripping solution (Merck) for $20 \mathrm{~min}$ at room temperature.

\section{Western blot analysis of human tissue}

Each sample of $100 \mathrm{mg}$ of human frontal cortex tissue (Brodmann Area 10) was dounce homogenized in RIPA containing protease (cOmplete Mini Protease Inhibitor Cocktail, Roche) and phosphatase (PhosSTOP, Roche). Homogenates were spun at $10,000 \times \mathrm{g}$ for $10 \mathrm{~min}$ at $4{ }^{\circ} \mathrm{C}$ to remove insoluble debris, and the resulting supernatant was reserved for Western blotting. 4-12\% pre-cast SDS polyacrylamide gels (Invitrogen) were loaded with $10 \mu \mathrm{g}$ protein per well and run at $120 \mathrm{~V}$ for $90 \mathrm{~min}$ in MES buffer (Invitrogen). Transfer to $0.2 \mu \mathrm{m}$ pore size nitrocellulose membrane took place at $90 \mathrm{~V}$ for $90 \mathrm{~min}$. The resulting membranes were rinsed briefly in TBS (blots for pTau were boiled for $3 \mathrm{~min}$ in PBS) and then blocked for $1 \mathrm{~h}$ in Li-Cor blocking buffer. Primary antibodies were applied overnight in blocking buffer. After rinsing in TBS, secondary infrared antibodies were applied the next day in blocking buffer (Li-Cor, 1:5000) and then imaged using an Odyssey CLX infrared imager. Blots were then stripped using NewBlot Nitrocellulose stripping buffer (Li-Cor) for $10 \mathrm{~min}$ at room temperature.

\section{Validation of pPTEN signal on western blot using phosphatase treatment}

Total brains from WT mice were solubilized in RIPA buffer supplemented with protease inhibitors followed by sonication, with a probe sonicator set of $20 \mathrm{~s}$ at a $20 \%$ power. Samples were centrifuged at $12 \mathrm{krpm}$ for $10 \mathrm{~min}$ at $4{ }^{\circ} \mathrm{C}$. Samples were then treated with lambda protein phosphatase according to the manufacturers' protocol (NEB). Protein samples were incubated with NEBuffer for protein metaldependent phosphatases and $\mathrm{MnCl}_{2}$ and increasing units of lambda protein phosphatase at $37^{\circ} \mathrm{C}$ for $30 \mathrm{~min}$. Western blot and analysis were then performed as described above.

\section{Immunofluorescence labeling}

For histology, mice were deeply anesthetized with sodium pentobarbital and brains were extracted following perfusion with PBS. Tissue was placed in 4\% paraformaldehyde (PFA) for $24 \mathrm{~h}$, and then transferred to a $30 \%$ sucrose solution in PBS. Once the brains were equilibrated, they were frozen on dry ice and sectioned on a Leica freezing sledge microtome at a thickness of $40 \mu \mathrm{m}$. Sections were stored at $-20^{\circ} \mathrm{C}$ in cryoprotectant solution. Sections were blocked for $1 \mathrm{~h}$ at RT in $10 \%$ BSA in PBS with $0.2 \%$ Triton X-100. Primary antibodies were diluted in blocking buffer at concentrations ranging from 1:100 to 1:1000 and sections were incubated at $4{ }^{\circ} \mathrm{C}$ in primary solution for $24-72 \mathrm{~h}$. After incubating in primary solution, sections were washed $3 \times$ for $5 \mathrm{~min}$ at RT in PBS. This was followed by a $1 \mathrm{~h}$ incubation with secondary antibodies conjugated to the appropriate fluorophores in PBS with $0.2 \%$ Triton-X. Sections were then washed in PBS with 4',6-diamidino-2-phenylindole (DAPI) $(1: 10,000)$ for 5 min at RT, followed by 2 washes in PBS for 5 min each at RT. They were then mounted on slides, and cover slipped using Vectashield hard-set mounting medium.

\section{Tissue imaging and analysis}

The tissue was imaged on a spinning-disk confocal system (Marianas; 3I, Inc.) consisting of an Axio Observer Z1 (Carl Zeiss) equipped with a CSU-W1 spinning-disk head (Yokogawa Corporation of America), ORCA-Flash4.0 v2 sCMOS camera (Hamamatsu Photonics), 63×1.4 NA PlanApochromat oil immersion objective. Image acquisition was performed using SlideBook 6.0 (3I, Inc.). Images consisting of $78 \mathrm{z}$-stacks at $0.13 \mu \mathrm{m}$ steps were obtained for images analyzed.

For the in vivo volume of CD68 analysis, a surface rendering was created for the channel being analyzed and the volume was quantified.

For the in vivo analysis of colocalization, image were deconvoluted in Huygens Pro. Using the Imaris software, a spots function was created for each channel, and the colocalized spots were counted using a distance cut-off of $100 \mathrm{~nm}$ between the edges of the spots.

For the in vivo percent area analysis, microglia numbers, and mean gray value images were analyzed with ImageJ software.

For in vivo engulfment analyses of PSD-95 and MAP2, a surface rendering was first created for CD68 and then used to mask the channel being measured for engulfment, all pixels outside the surface being set to 0. A surface was then created for the masked channel and the volume of the surface was quantified.

For the in vivo analysis of the PTEN mean gray value within pTau positive and pTau negative areas, a maximum intensity z-stack of the image was created. The corresponding pTau channel was thresholded and a mask was created and added to the region of interest (ROI) manager. The pTau mask was then added to the PTEN channel, the area outside the mask was cleared for assessment of PTEN mean gray value within Tau positive areas, and the area inside the mask was cleared for assessment of PTEN mean gray value in Tau negative areas.

\section{Flow cytometry}

The synaptosome-containing pellet (above) was resuspended in binding buffer (10 mM HEPES pH 7.4), $150 \mathrm{mM} \mathrm{NaCl}$, $5 \mathrm{mM} \mathrm{KCl}, 5 \mathrm{mM} \mathrm{MgCl}_{2}, 1.8 \mathrm{mM} \mathrm{CaCl}_{2}$ ), after which $100 \mu \mathrm{l}$ 
aliquots were incubated for $30 \mathrm{~min}$ at $20-25{ }^{\circ} \mathrm{C}$ with dye solution and then diluted in PBS (final volume, $1000 \mu \mathrm{l}$ ) for immediate flow cytometry analysis. Final dye concentration was $1 \mu \mathrm{M}$ for Calcein AM Blue (Invitrogen) and $5 \mu \mathrm{l} / \mathrm{ml}$ for p-SIVA (Novus Bio.). The synaptosomes were analyzed on a BD FACSAria Cell Sorter.

\section{Live imaging of membrane asymmetry}

Cortical neurons were plated on live cell imaging dishes with four chambers. On DIV20, Neurobasal medium was removed and replaced with $1 \mathrm{ml}$ pre-warmed Live Cell imaging solution (Gibco) with $1 \mu \mathrm{F} 2 \mathrm{~N} 12 \mathrm{~S}$ membrane asymmetry dye (ThermoFisher). Neurons were incubated at $37^{\circ} \mathrm{C}$ for $5 \mathrm{~min}$ before imaging using an LSM 710 Zeiss confocal microscope. The dye was excited using a $405 \mathrm{~nm}$ laser line, with emission simultaneously being captured at 535 and $585 \mathrm{~nm}$, using dual camera acquisition. 5 separate XY coordinates were programmed and imaged sequentially 5 times. Images were analyzed using the Ratio Plus plugin in ImageJ. Each data point is the average of 5 images taken at each XY coordinate.

\section{Pharmacological inhibition of PTEN}

Mice from both genders were randomized and separated into groups of five. The mice received intraperitoneal injections of the PTEN inhibitor dipotassium bisperoxovanadium(pic) dihydrate (bpv(pic)) (Merck) at $1 \mathrm{mg} / \mathrm{kg}$, or $0.9 \%$ saline twice weekly for 5 months.

\section{Reagents}

A list of critical reagents and resources can be found in Supplementary Table 1.

\section{Statistical analysis}

All statistical analyses were performed using GraphPad Prism 7, with statistical tests used as per figure legend. Statistical significance was defined as: n.s.-not significant, $* p<0.05, * * p<0.01, * * * p<0.001, * * * * p<0.0001$. Data throughout the paper are displayed as mean \pm SEM. Experimenters were blinded whenever possible to experimental condition during data acquisition or quantification.

\section{Results}

\section{Increased caspase-3 cleavage and exposure of 'eat-me' signals in tauopathy}

PTEN functions as a tumor suppressor to promote apoptosis by antagonizing the pro-survival pathway [30]. We therefore sought to determine whether apoptosis was occurring in the $\mathrm{rTg} 4510$ mouse strain that expresses human Tau with the P301L FTLD-Tau mutation and presents with age-dependent progressive Tau pathology [41]. We assessed rTg4510 and wild-type (WT) littermate control mice at 2 and 6 months for the presence of cleaved caspase-3, an end stage marker of apoptosis [12]. We found increased neural apoptosis at 6 months of age, as evidenced by cleaved caspase-3-positivity in CA1 pyramidal cell layer neurons that were identified using the neuronal marker microtubule-associated protein 2 (MAP2) (Fig. 1a-c). Accelerated apoptosis was also apparent in primary cortical neurons obtained from $\mathrm{rTg} 4510$ mice (Fig. S1a).

During apoptosis, plasma membranes lose their molecular asymmetry through a mechanism by which PS, a negatively charged amine-containing phospholipid, becomes externalized to the outer leaflet of the cell membrane [34]. We therefore sought to determine whether PS is exposed outside of the cell membrane in tauopathy by probing $\mathrm{rTg} 4510$ and WT primary neurons with the membrane asymmetry probe F2N12S, which responds to changes in the charge of the membrane following PS exposure [9, 11, 20, 25, 49]. Live imaging of $\mathrm{rTg} 4510$ compared to WT primary neurons labeled with F2N12S revealed a pronounced gain in membrane symmetry, indicating increased exposure of PS in the presence of pathological Tau (Fig. 1d).

Having determined that primary neurons obtained from rTg4510 mice expose PS, we next sought to determine whether this exposure is also found at the synapse. We therefore isolated synaptosomes from $\mathrm{rTg} 4510$ and WT mice and incubated them with both the membrane-impermeable marker p-SIVA, a polarity-sensitive annexin probe that labels exposed PS [26], and the membrane-permeable dye Calcein Blue AM, which becomes fluorescently active inside sealed and intact membranes [8]. Our results revealed no detectable difference between the two genotypes at 2 months of age; however, at 6 months of age, $\mathrm{rTg} 4510$ mice displayed an increase in synaptosomes with a high fluorescence signal for both p-SIVA and Calcein AM Blue (Fig. 1e).

PS exposure can be detected in the brain via the 'eat-me' signal C1q that binds to PS $[16,37,56,63]$. We found that the $\mathrm{C} 1 \mathrm{q}$ intensity in the hippocampus of $\mathrm{rTg} 4510$ mice was significantly increased between 2 and 6 months of age, an effect that was not observed in WT mice (Fig. 2a). Automated counting and analysis of C1q puncta in deconvoluted confocal images confirmed an increase in $\mathrm{rTg} 4510$ mice (Fig. 2b, d). We also observed an increase in the fraction of PSD-95 co-localized with C1q in these mice (Fig. 2e). Despite the decrease in numbers of PSD-95 puncta that reflects the synapse loss seen in this mouse strain (Fig. 2c), the total number of PSD-95/C1q interactions was increased (Fig. 2f). Together, we revealed that Tau promotes the 

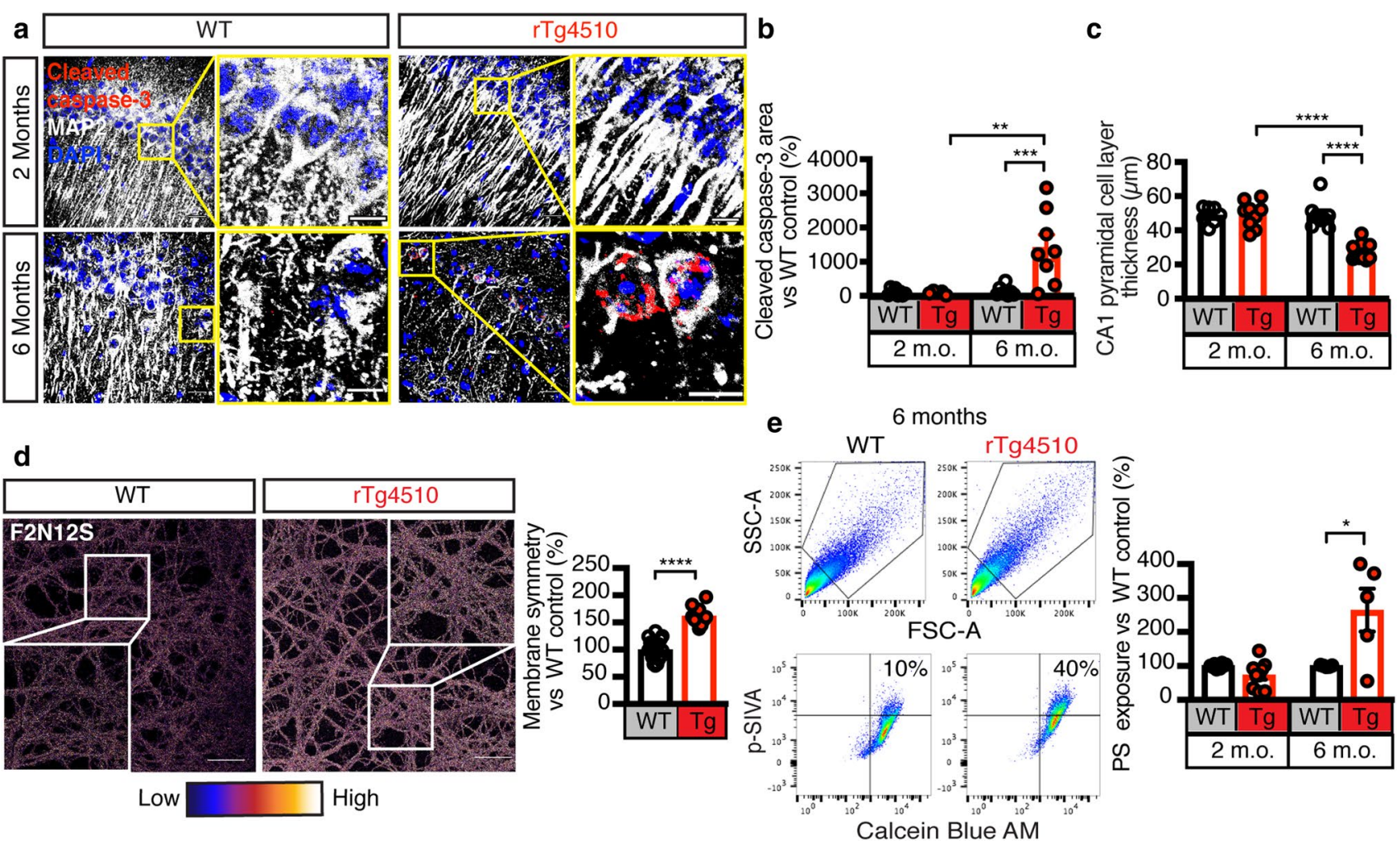

Fig. 1 Increased apoptotic hallmarks cleaved caspase-3 and phosphatidylserine exposure in $\mathrm{rTg} 4510$ mice. a-c Maximum intensity z-projection images of the hippocampus of 2 and 6 month-old rTg4510 and WT mice probed with the apoptosis marker Cleaved caspase-3 (red), the neuronal marker MAP2 (white) and the nuclear marker DAPI (blue). Quantification of the images reveals a massive increase in neuronal apoptosis and cell loss in $\mathrm{rTg} 4510$ mice at 6 months. Scale bars: $20 \mu \mathrm{m}$. d Representative images and quantification of WT and $\mathrm{rTg} 4510$ primary neurons labeled with the membrane asymmetry probe F2N12S. A higher ratio (pseudo-colored as lowblue to high-white) indicates more membrane symmetry and correlates with the exposure of negatively charged phospholipids including

exposure of PS, which facilitates the removal of neuronal structures and synapses by microglia.

\section{Increased microglial engulfment of synapses and neuronal structures in rTg4510 mice}

To understand how microglia respond to the pathological Tau built-up in the $\mathrm{rTg} 4510$ hippocampus, we counted the number of microglia and the percentage area covered by them in comparison to WT mice. At 2 months of age, these parameters did not differ between the two genotypes; at 6 months, however, $\operatorname{rTg} 4510$ mice had significantly more microglia per region of interest (ROI), compared to 2 monthold rTg4510 and 6 month-old WT mice (Fig. 3a-c). We next investigated microglial phagocytosis by assessing the microglial lysosomal marker Cluster of Differentiation 68 (CD68) and found an increased volume in the hippocampus
PS on the surface. This provides evidence that there is more PS exposure in $\mathrm{rTg} 4510$ neurons. Inset is zoomed-in image of white framed region. Scale bars: $10 \mu \mathrm{m}$. e Representative plots and quantification of the flow cytometry analysis of apoptotic PS exposure (p-SIVA $\left.{ }^{+}\right)$ on viable (Calcein Blue $\mathrm{AM}^{+}$) synaptosomes obtained from 2 and 6 month-old WT and rTg4510 mice. This analysis indicates that when comparing equal fractions of viable synaptosomes, there is a greater proportion of apoptotic synaptosomes in $\mathrm{rTg} 4510$ than WT mice. Unpaired $t$ test within the same age group. Data are presented as mean \pm SEM, $* p<0.05, * * p<0.01, * * * p<0.001, * * * * p<0.0001$; b, c two-way ANOVA with Tukey's multiple comparison test, e, f unpaired $t$ test

of both 2 and 6 month-old rTg4510 mice compared to WT controls (Fig. 3d, e). The average size of these lysosomes was increased in the rTg 4510 hippocampus compared to WT mice at 6 months of age and they were significantly larger than those of 2 month-old rTg4510 mice (Fig. 3f).

We next used spinning-disk confocal microscopy followed by surface rendering to determine whether PSD95 was internalized into CD68-labeled lysosomes. We found that the volume of engulfed PSD-95 structures was increased in the hippocampus of 6 month-old rTg 4510 mice compared to WT controls (Fig. $3 \mathrm{~g}$ ). To assess to which extent synaptosomes were internalized by microglia, we incubated rTg4510 and WT synaptosomes with pHrodo-AM, a dye that fluoresces in an acidic environment such as the lysosome, and added them to primary EGFP-labeled microglia isolated from $\mathrm{Cx} 3 \mathrm{Cr} 1^{\mathrm{eGFP} /-}$ mice. We found that the pHrodo intensity increased at a faster 


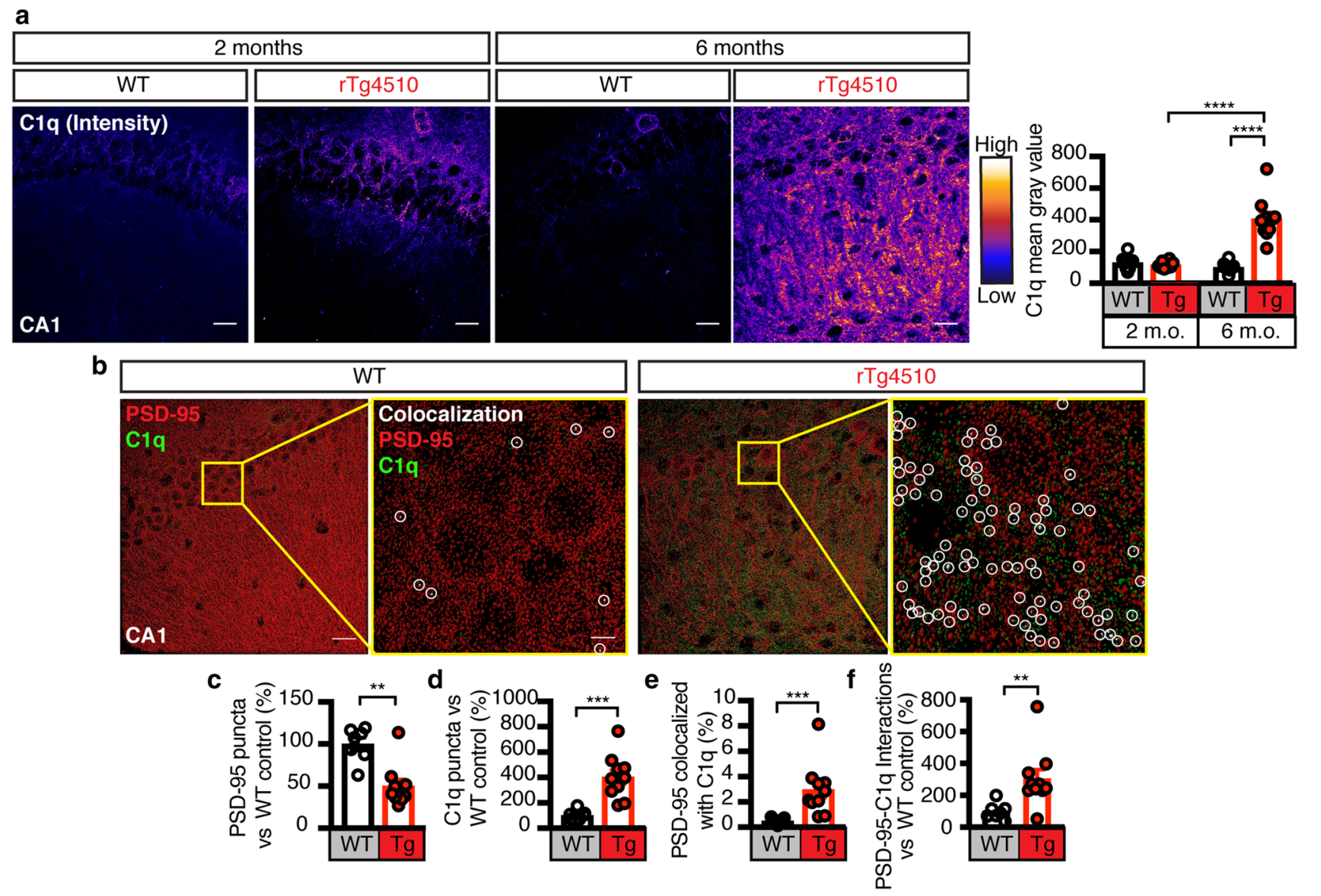

Fig. 2 Increase of complement factor $\mathrm{C} 1 \mathrm{q}$ and its association with PSD-95 in $\mathrm{rTg} 4510$ mice. a Representative fluorescence images and analysis for $\mathrm{Clq}$ (pseudo-colored from low-blue to high-white) from the CA1 region of 2 and 6-month-old $\operatorname{rTg} 4510$ and WT mice. The analysis reveals an increase in C1q intensity between 2 and 6 months in $\operatorname{rTg} 4510$ mice and an increase between $\mathrm{rTg} 4510$ and WT mice at 6 months. b 3D spots rendering of PSD-95 (red), and C1q (green) from $(\mathrm{C})$ following deconvolution. Zoomed-in images with yellow border display colocalization of PSD-95 and C1q in white (circled). Scale bar: $20 \mu \mathrm{m}$; zoomed-in image: $5 \mu \mathrm{m}$. c Quantification of the number of PSD-95 puncta in the WT and rTg4510 hippocampus,

rate in the $\mathrm{rTg} 4510$ synaptosomes than in the WT samples, and remained at an elevated level throughout the $\sim 4 \mathrm{~h}$ of the experiment (Fig. 3i). Total engulfment was also assessed by measuring the area under the curve, which revealed that microglia engulfed more synaptosomes from rTg4510 than WT mice (Fig. 3j). We reasoned that the engulfment of neuronal structures by microglia may not be limited to the postsynaptic density (PSD). To confirm this, we repeated the in vivo engulfment measurements using MAP2 as a proxy for neuronal structures that may be taken up in addition or independently of PSD-95. We found that microglia in the $\mathrm{rTg} 4510$ had increased MAP2 structures located within CD68-labeled lysosomes compared to WT controls (Fig. 3k). showing a significant loss in PSD-95 occurring in $\mathrm{rTg} 4510$ mice at 6 months of age. d Quantification of C1q puncta between WT and rTg4510 mice, indicating a large increase in the total number of $\mathrm{C} 1 \mathrm{q}$ puncta in $\mathrm{rTg} 4510$ mice. e Quantification of the fraction of total PSD95 tagged with C1q, indicating that despite a loss of PSD-95, there is a greater fraction of PSD-95 that is associated with C1q. $\mathbf{f}$ Analysis of the number of colocalized PSD-95/C1q puncta demonstrating that in rTg4510 mice more PSD-95 is tagged with the "eat-me" signal C1q. Data presented as mean \pm SEM, ${ }^{*} p<0.05, * * p<0.01, * * * p<0.001$, $* * * * p<0.0001$; a two-way ANOVA with Tukey's multiple comparison test, $\mathbf{c}, \mathbf{d}, \mathbf{e}, \mathbf{f}$ unpaired $t$ test

\section{PTEN activation precedes caspase-3 cleavage, with levels correlating with those of pTau}

We next assessed the pathological phosphorylation of Tau (pTau) at the early epitope Tyrosine 18 (pY18) $[2,3,36]$ in relation to PTEN expression and distribution in $\mathrm{rTg} 4510$ mice using immunofluorescence (Fig. 4a). This revealed increased PTEN levels in the hippocampus at 6 , but not 2 months of age compared to WT littermate control mice (Fig. 4a, b). Interestingly, PTEN expression was increased with age in both genotypes (Fig. $4 a$, b). In relation to pY18 Tau, we revealed in 6 month-old $\mathrm{rTg} 4510$ mice that PTEN expression was higher in Tau-positive neurons compared to those which stained negative for pTau (Fig. 4c). 

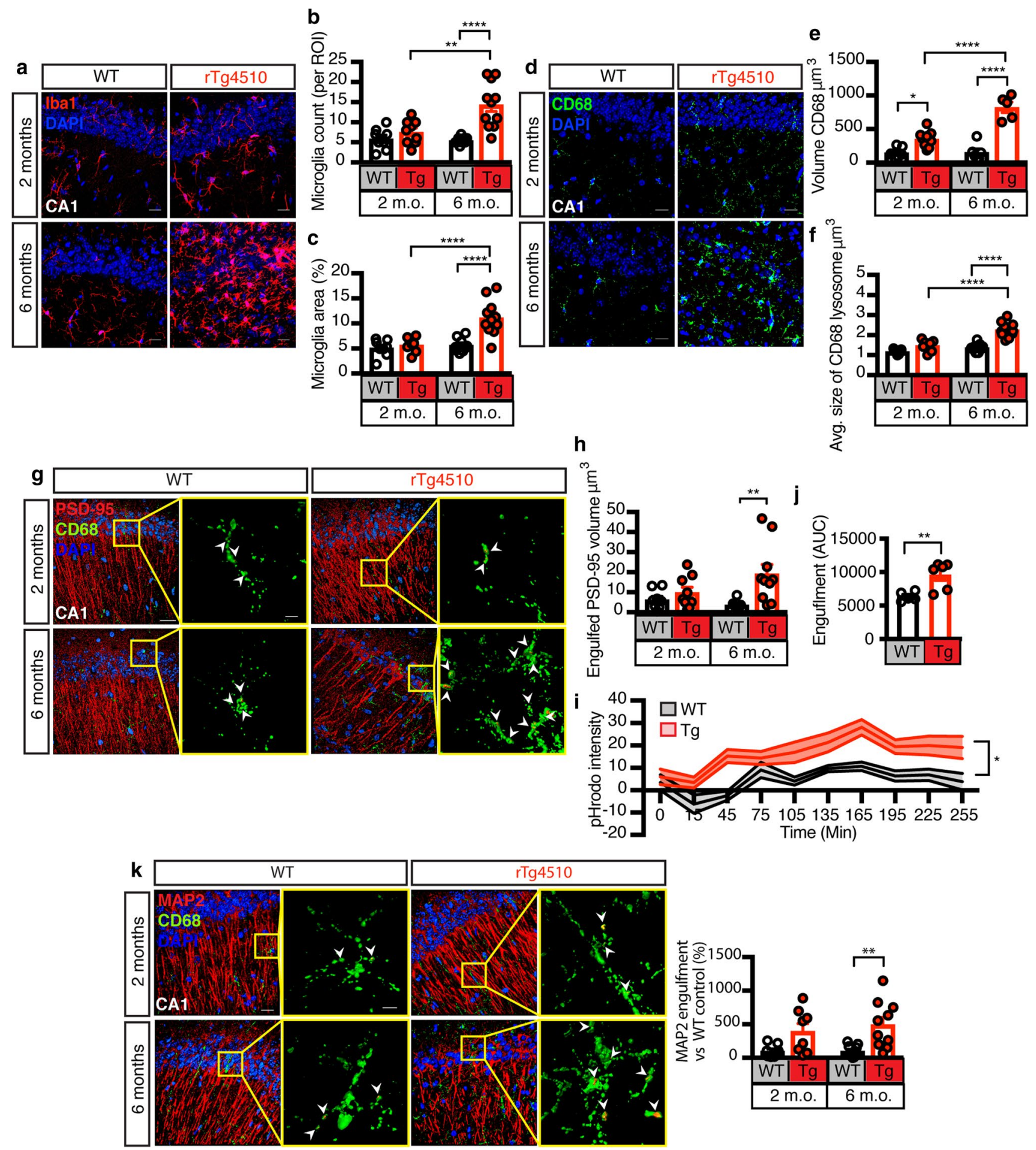

To determine whether levels of pY18 Tau correlated with those of PTEN, we measured pY18 Tau intensities in the hippocampus of rTg4510 mice at 2 and 6 months of age and plotted them against PTEN, which revealed a positive correlation (Fig. 4d). This was also observed in the cortex, another region with Tau pathology in this mouse strain (Fig. S2a-c).
Of the four critical residues that negatively regulate PTEN activity [4], only S380, T382 and T383 (together referred to here as pPTEN) are detectable by antibody-based methods. We assessed the ratio of total PTEN to pPTEN (i.e. inactive PTEN) (Fig. 5a) as a measure of activity in $\mathrm{rTg} 4510$ brains, with an increase in this ratio corresponding to an increase in activity. To validate the specificity of the PPTEN antibody 
4Fig. 3 Microglia increasingly engulf neurons and synapses in rTg4150 mice. a Representative fluorescence maximum intensity z-projections for the microglial marker Ibal (red) and the nuclear marker DAPI (blue) in the CA1 region of 2 and 6 month-old WT and rTg4510 mice. Scale bar: $20 \mu \mathrm{m}$. b Quantification of microglia per ROI from a, counting DAPI- and Iba1-positive cells. This analysis provides evidence of microgliosis in $\mathrm{rTg} 4510$ mice. c Quantification of microglia area per ROI from a, analyzed by thresholding the Iba1 signal. Together with $\mathbf{b}$ this analysis provides evidence of microgliosis in $\mathrm{rTg} 4510$ mice. d Representative fluorescence maximum intensity z-projections of the microglial lysosomal marker CD68 (green) and DAPI (blue) in the CA1 region of 2 and 6 month-old WT and rTg4510 mice. Scale bar: $20 \mu \mathrm{m}$. e Quantification of the volume of CD68 from (D), measured by surface rendering in Imaris. This analysis demonstrates that microglial lysosome production, a proxy for phagocytic activity, is increased in $\mathrm{rTg} 4510$ mice. f Quantification of the average volume of individual CD68 lysosomes from (D), measured by surface rendering in Imaris. g 3D rendering of the postsynaptic marker PSD-95 (red), CD68 (green) and DAPI (blue), with arrowheads indicating engulfment. $\mathbf{h}$ Quantification of the volume of PSD-95 engulfed by microglia in the hippocampus of 2 and 6 month-old $\mathrm{rTg} 4510$ and WT mice. This analysis provides evidence of microglia engulfment of synaptic structures in $\mathrm{rTg} 4510$ mice. Scale bar in composite image: $20 \mu \mathrm{m}$; scale bar in zoomed-in images: $5 \mu \mathrm{m}$. i Time course quantification of synaptosomal engulfment by microglia using the acidification sensor pHrodo-AM red. Data points at each time segment represent individual animals analyzed in triplicates. This analysis demonstrates that synaptosomes from $\mathrm{rTg} 4510$ mice are primed for engulfment by microglia. $\mathbf{j}$ Quantification of the area under the curve from $\mathbf{i}$, representative of total engulfment. k 3D rendering of the neuronal marker MAP2 (red), CD68 (green) and DAPI (blue), with arrowheads indicating engulfment. Quantification of MAP2 engulfment by microglia in the hippocampus of 2 and 6 month-old rTg4510 and WT mice. This analysis provides evidence of microglia engulfment of neuronal structures in $\mathrm{rTg} 4510$ mice. Scale bar in composite image: $20 \mu \mathrm{m}$; scale bar in zoomed-in images: $5 \mu \mathrm{m}$. Data presented as mean \pm SEM, $* p<0.05, * * p<0.01$, $* * * * p<0.0001 ; \mathbf{b}, \mathbf{c}, \mathbf{e}, \mathbf{f}, \mathbf{h}, \mathbf{i}$ and $\mathbf{k}$ two-way ANOVA with Tukey's multiple comparison test, $\mathbf{j}$ unpaired $t$ test

in mouse samples, we incubated lysates with increasing concentrations of phosphatase, which identified the upper of the two bands (which was hence used for quantification) as being specific for pPTEN (Fig. S3a).

We analyzed total protein lysates from the hippocampus of rTg4510 and WT mice at three time points $(2,4$, and 6 months), and observed an increased ratio of activated PTEN in rTg4510 compared to WT mice at 2 and 4 months of age (Fig. 5b). Similarly, total protein lysates from the cortex also revealed an age-dependent increase in PTEN activation (Figure S3b).

Under pathological conditions, Tau re-localizes to the somatodendritic compartment and also accumulates in the PSD where it exerts synaptotoxicity [10, 22]. We confirmed the presence of pathological Tau in the PSD at the earliest time-point using purified PSD fractions from 2 monthold rTg4510 and WT mice, and analyzed total and pY18 Tau levels by immunoblotting. We found abundant levels of pY18 Tau in both the hippocampal and cortical PSD fractions (Fig. S3c). We next analyzed PTEN activation in synaptosomal fractions (which contain both the pre- and post-synapse) from the hippocampus of 2, 4, and 6 monthold WT and rTg4510 mice. Immunoblotting of total and phosphorylated PTEN revealed an increase in PTEN activity in rTg4510 compared to WT in 4 and 6 month-old mice (Fig. 5c), a pattern also found in cortical synaptosomal fractions (Figure S3d).

To determine whether PTEN is also activated in a tauopathy model with a much less pronounced pathology, we examined cortical brain lysates from the K3 mouse strain, which expresses human Tau together with the FTLD-Tau mutation K369I [21]. These mice present with widespread Tau pathology in the cortex [38]. We found increased PTEN activation in total cortical lysates from 12 monthold K3 mice compared to WT animals (Figure S3e). We next sought to determine whether the effect was specific to Tau, or whether another aggregated protein, $A \beta$, elicited a similar response. We therefore assessed PTEN levels and activation in the A $\beta$-depositing APP23 mouse model [55]. Interestingly, western blot analysis of total protein isolated from whole brains of 12 month-old APP23 mice revealed a significant decrease in PTEN activation in APP23 compared to WT mice, with no change in total PTEN levels between the two groups (Fig. S3f).

\section{Inhibition of PTEN with $\mathrm{bpV}$ reduces protein phosphatase activity without altering levels or phosphorylation of Tau}

To confirm the involvement of PTEN in the neuron and synapse loss seen in the rTg4510 mice, we chose to inhibit PTEN pharmacologically using bisperoxovanadium(pic) $(\mathrm{bpV})$. This compound is a protein tyrosine phosphatase (PTPase) inhibitor that readily crosses the blood-brain barrier [44] and that was shown to inhibit neuronal PTEN after systemic application, reducing apoptosis in development and under pathological conditions such as ischemia, trauma and oxidative stress [60]. As PTEN's PTPase ability has been shown to be required for its ability to promote synapse loss [67], we sought to determine whether chronic inhibition of PTEN would be effective in preventing synapse loss in rTg4510 mice. We first validated the effect of bpV by intraperitoneally (i.p.) injecting $1 \mathrm{mg} / \mathrm{kg} b \mathrm{bV}$ or saline as a control into 6 month-old WT mice and determined the phosphorylation of focal adhesion kinase (FAK), a known substrate of PTEN's PTPase activity [59, 66], after 6, 24, and $48 \mathrm{~h}$. We found that levels of pY397 FAK were increased at both the 24 and $48 \mathrm{~h}$ time-points relative to the saline control (Fig. 6a). We therefore delivered $\mathrm{bpV}$ twice weekly by i.p. injections ( $1 \mathrm{mg} / \mathrm{kg}$ ), over a 5 month period (Fig. $6 \mathrm{~b})$.

At the end of the chronic treatment with $\mathrm{bpV}$, mice were sacrificed $48 \mathrm{~h}$ after the final injection, followed by analysis of several components of the PTEN lipid and 


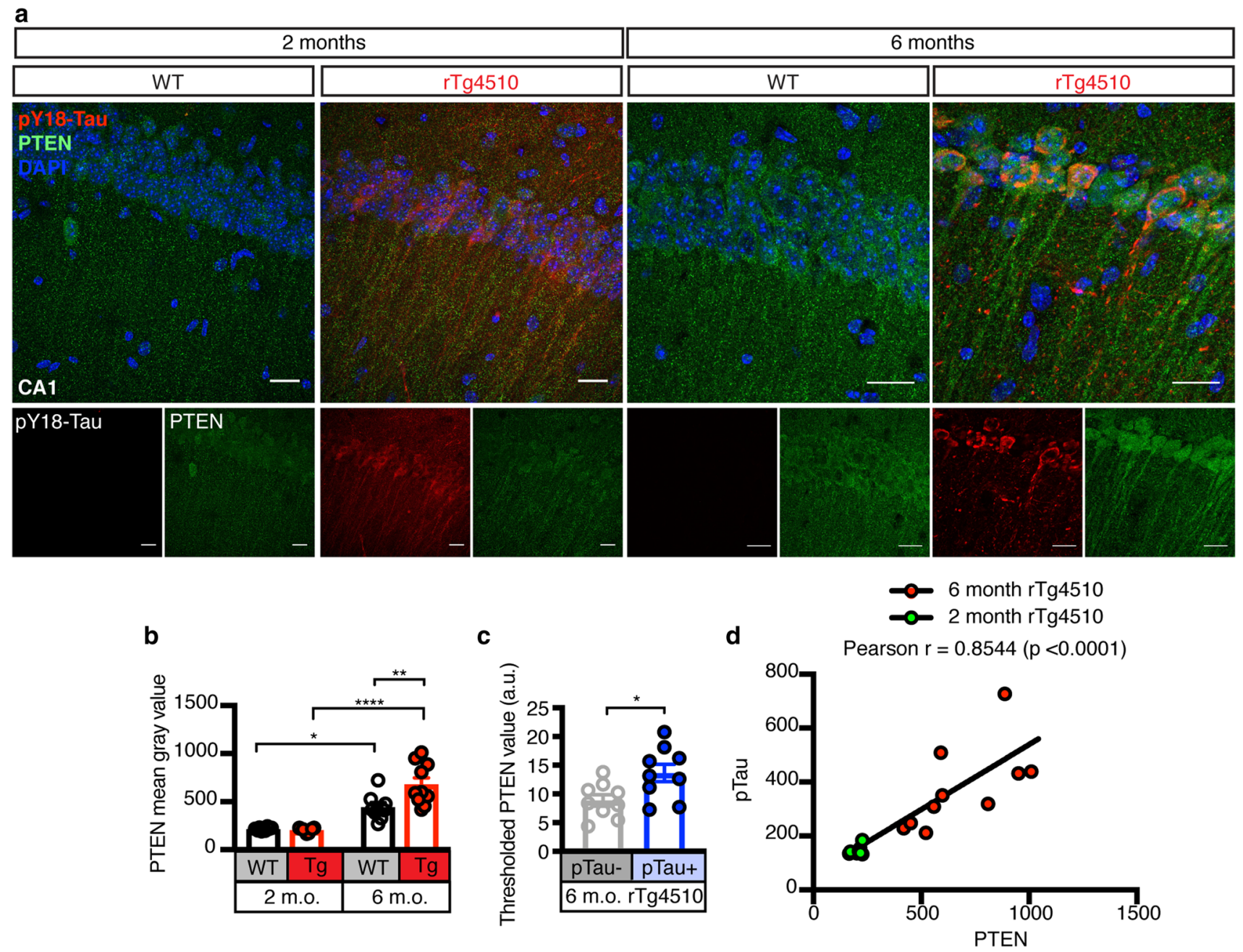

Fig. 4 PTEN levels increase and correlate with pTau in the hippocampus of rTg4510 mice. a Representative fluorescence images for Tau phosphorylated at Tyr18 (pY18 Tau, red), PTEN (green), and DAPI (blue) obtained from $10 \mu \mathrm{m}$ thick maximum intensity z-projections of the hippocampus (CA1 region) of 2 and 6 month-old Tau P301L transgenic rTg4510 and WT mice. Scale bar: $20 \mu \mathrm{m}$. b Quantification of the PTEN mean gray value in the hippocampus of 2 and 6 month-old rTg4510 and WT mice, demonstrating that PTEN lev-

protein phosphatase pathways. As expected, we found that PTEN inhibition by bpV did not change its phosphorylation status (Fig. 6c). In the protein phosphatase pathway, we found that FAK phosphorylation at Y397 was only increased in the bpV-treated WT group; however, as this protein is a substrate of PTEN, we reasoned that the increased activation of PTEN counteracts the change seen after inhibition by $\mathrm{bpV}$ and that there are multiple tyrosine phosphorylation sites on FAK that could be further analyzed. In the PTEN lipid phosphatase pathway we saw no changes to pS473 AKT (Fig. 6c). To determine if PTEN inhibition would affect Tau levels and phosphorylation an els increase with age in $\mathrm{rTg} 4510$ mice. c Quantification of the PTEN mean gray value in pTau- and pTau + areas of 6 month-old rTg4510 mice, indicating enrichment of PTEN in neurons that are accumulating pTau. d Pearson correlation between the PTEN and pY18 Tau mean gray values revealing age-dependency. Data presented as mean $\pm \mathrm{SEM}, * p<0.05, * * p<0.01, * * * * p<0.0001$; b two-way ANOVA with Tukey's multiple comparison test, $\mathbf{c}$ unpaired $t$ test, $\mathbf{d}$ Pearson correlation

immunoblot analysis of total brain extracts from bpV-and saline-treated $\mathrm{rTg} 4510$ and WT mice was performed. This revealed neither a change in total Tau relative to total protein nor phosphorylation of Tau as evaluated for a range of pathological epitopes (Y18, S404, S205/T205 and T231) relative to total Tau (Fig. 6d), suggesting that these pathological Tau phosphorylation sites are upstream of PTEN. Based on these findings we conclude that chronic treatment with bpV over a 5 month-period intermittently reduces PTEN's PTPase activity in WT and rTg4510 mice and does not affect Tau levels or phosphorylation. 


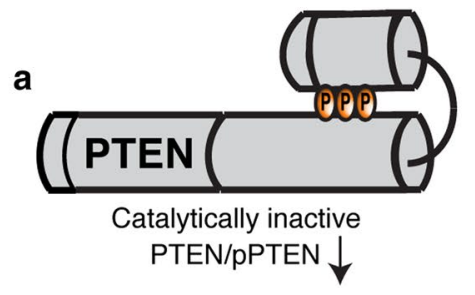

b

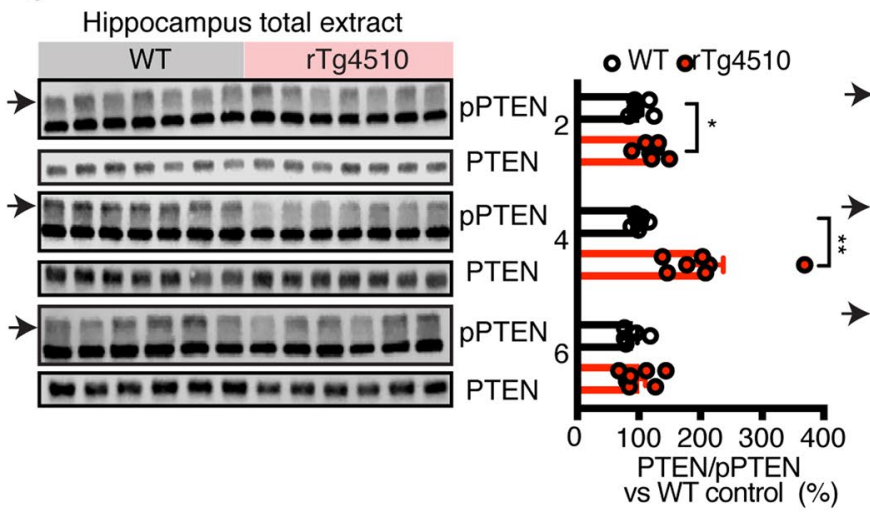

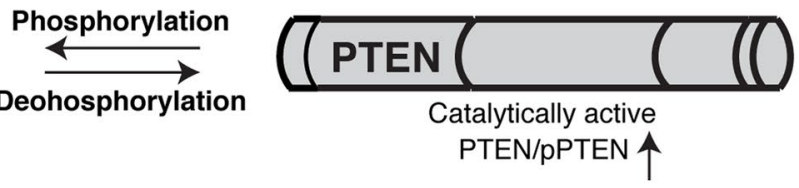

C Hippocampal synaptosomes

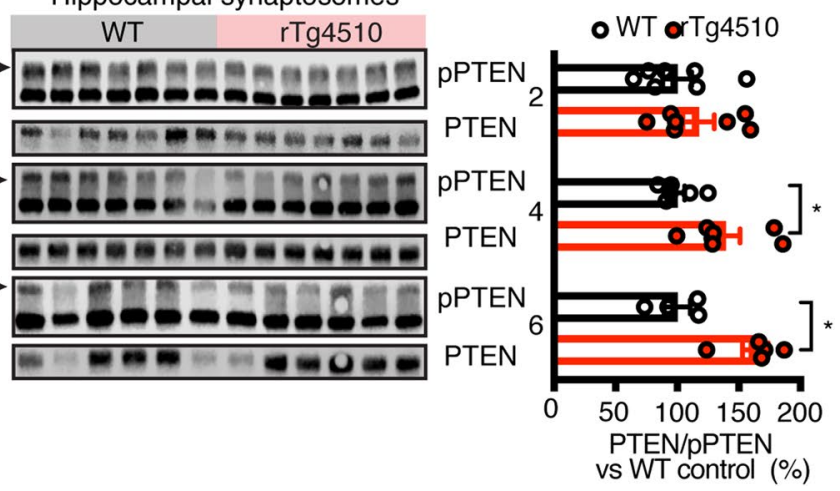

Fig. 5 Increased PTEN activation in $\mathrm{rTg} 4510$ mice, preceding caspase- 3 cleavage. a Schematic depicting negative regulation of PTEN activity by phosphorylation. b Representative western blots and quantification of pPTEN (inactive) and total PTEN using extracts from the hippocampus of 2, 4, and 6 month-old WT and rTg4510 mice reveal an increase in total PTEN levels relative to the inactive form at 2 and 4 months. c Representative western blots and quantification

\section{Inhibition of PTEN reduces loss of neurons and synapses in rTg4510 mice}

The major functional outcome we sought to investigate was the effect PTEN inhibition has on synapse and neuron loss. We therefore quantified the number of pyramidal cell nuclei (using DAPI) in the CA1 region. This revealed that $\mathrm{bpV}$ treatment prevented neuronal loss in $\mathrm{rTg} 4510$ mice (Fig. 7a), whereas no changes were observed in WT mice. We next quantified levels of PSD-95 by immunoblotting, revealing a significant increase in bpV-treated $\mathrm{rTg} 4510$ mice (Fig. 7b). Again, WT mice exhibited no difference in response to bpV versus saline treatment (Fig. 7b). The bpV-treated rTg4510 mice also displayed a significantly reduced volume of CD68-positive lysosomes (Fig. 7c, d). We performed high resolution spinning-disk confocal microscopy followed by surface rendering to quantify the amount of PSD-95 internalized by CD68-positive lysosomes, revealing significantly less PSD-95 in lysosomes from $b p V$-treated compared to saline-treated $\mathrm{rTg} 4510$ mice (Fig. 7c, e). These data provide evidence that PTEN inhibition prevents microglia-mediated synapse loss in rTg4510 mice, and that PTEN acts downstream of Tau. of pPTEN (inactive) and total PTEN of synaptosomal lysates from the hippocampus of 2, 4, and 6 month-old WT and rTg4510 mice, revealing an increase in total PTEN relative to the inactive form at 4 and 6 months. Data presented as mean \pm SEM, ${ }^{*} p<0.05$, ${ }^{* *} p<0.01$, b, c unpaired $t$ test performed between WT and $\mathrm{rTg} 4510$ at each age group independently

\section{PTEN activation displays dichotomous relationship with age in humans and mice}

PTEN accumulates in AD brains bearing neurofibrillary tangles [50]; however, what the activation status is of PTEN in FTLD-Tau brains is not known. Therefore, we assessed the ratio of total PTEN to pPTEN as a measure of activity in FTLD-Tau brain samples, P301L mutation carriers and healthy controls, revealing a non-statistically significant trend in increased active PTEN in the frontal cortex of diseased brains compared to healthy samples (Fig. 8a, b), whereas total levels did not differ between the three groups (Fig. 8a, c). To account for the high level of variability in our samples, we plotted the PTEN/pPTEN ratio against age for combined familial and sporadic disease patients and healthy controls. This revealed a negative relationship between age and PTEN activation in the disease group, and a positive relationship in the control group (Fig. 8a, d).

Having observed a negative relationship between age and PTEN activation in FTLD-Tau patient brains we hypothesized that there may be early and late stage differences in PTEN activation during tauopathy. To determine if PTEN activation rises early in disease pathogenesis and falls 


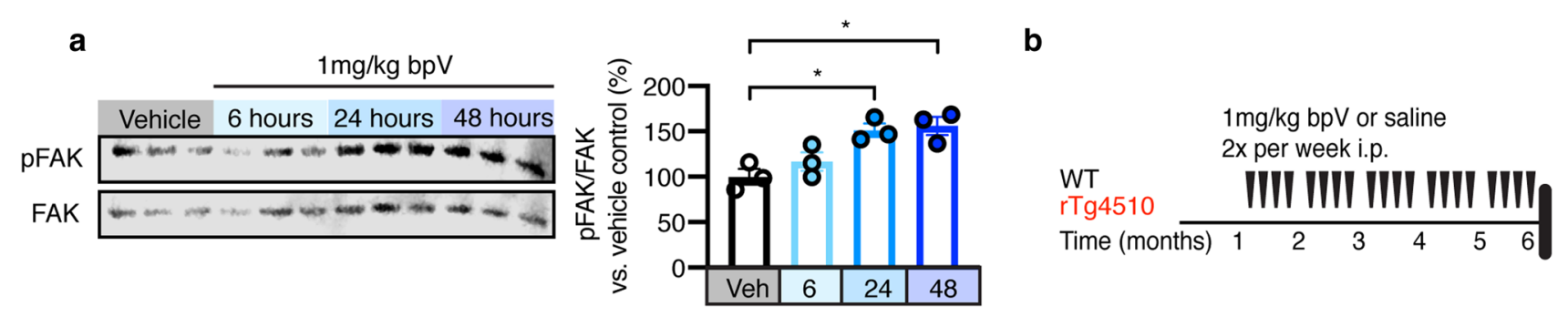

C Whole brain (total extract) Saline bpV Saline bpV

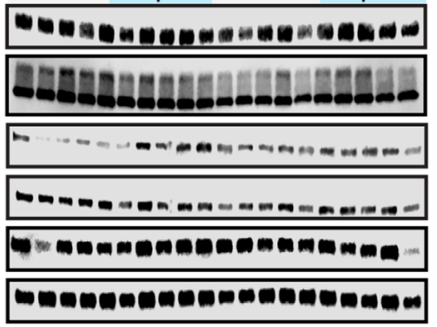

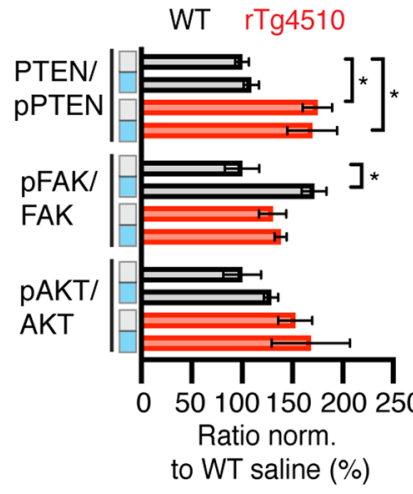

d Whole brain (total extract) WT rTg4510
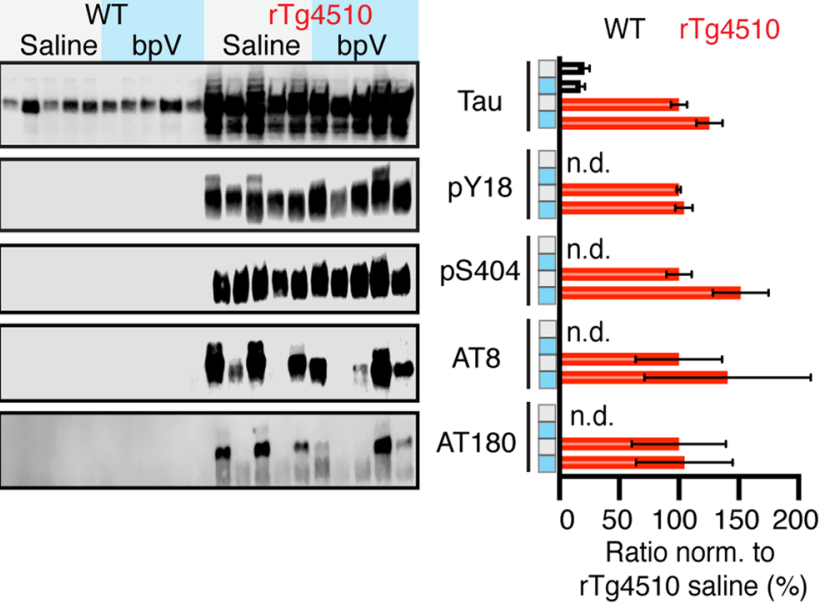

Fig. 6 PTEN inhibition with bpV alters protein phosphatase pathway without reducing Tau levels or phosphorylation. a Representative western blots and quantification of pY397 FAK and total FAK in 6 month-old WT mice 6,24, and $48 \mathrm{~h}$ after injection with bpV or saline control. b Study design of PTEN inhibition with bpV, injected intraperitoneally (i.p.) twice weekly for 5 months (starting at 1 month of age). c Representative western blots and quantification of pPTEN relative to PTEN, pY397 FAK relative to total FAK, and pS473 AKT relative to total AKT in brain lysates from saline- or bpV-treated

at later stages, we analyzed additional age groups of the rTg4510 line. In total protein extracts from whole brains of 6 and 12 month-old rTg4510 and WT mice, PTEN activation was significantly increased in the $\mathrm{rTg} 4510$ mice at both time points (Fig. 8e). At 15 months, we found comparable PTEN activation in the two genotypes, whereas at 18 months of age, activation decreased significantly in the rTg4510 mice (Fig. 8e), with the later time points more closely resembling what we had found in FTLD-Tau patient brains.

\section{Discussion}

Phosphatase and tensin homolog (PTEN) regulates synaptic density during brain development [29]. Here, we reveal that PTEN has also a critical role in the neuronal and synaptic loss that characterizes tauopathy [15]. Using the tauopathy mouse model $\mathrm{rTg} 4510$, we found a significant decrease in PTEN phosphorylation, indicative of its activation [67] in
rTg4510 and WT mice. The quantified ratio is expressed as a percent normalized to the saline-treated WT group. c Representative western blots and quantification of total Tau relative to total protein and pY18, pS404, pS202/T205 and pT231 each relative to total Tau in brain lysates from saline- or bpV-treated $\mathrm{rTg} 4510$ and WT mice. The quantified ratio is expressed as a percent normalized to the saline-treated rTg4510 group. Data presented as mean \pm SEM, $* p<0.05$, a oneway ANOVA with Tukey's multiple comparison test, $\mathbf{b}, \mathbf{c}$ two-way ANOVA with Tukey's multiple comparison test

neurons and synapses. This activation of PTEN preceded the apoptotic signatures caspase-3 cleavage and PS exposure, and was followed by microglial phagocytosis of neuronal structures. We further validated our PTEN findings in an additional tauopathy strain, the $\mathrm{K} 3$ mice, and confirmed that the effect was specific to Tau, as increased PTEN activation was observed in $\mathrm{K} 3$ mice, but not in $\mathrm{A} \beta$ plaque-forming APP23 mice. Moreover, chronic administration of the PTEN inhibitor bpV over 5 months to $\mathrm{rg} 4510$ mice alleviated the synaptic and neuronal degeneration, as well as decreased microglial phagocytosis of synapses. Although several studies have shown that PTEN regulates synaptic density [29, 40, 67], our study is the first to reveal an involvement of PTEN in the process of synaptic elimination by microglia.

A recent study reporting that synapse loss in $\mathrm{AD}$ is mediated by complement and microglia has opened the door to obtain further mechanistic insight into this process [18]. Tau accumulates in the synapse, where it mediates the synaptotoxicity of $A \beta[19,22]$, and at the same 
a
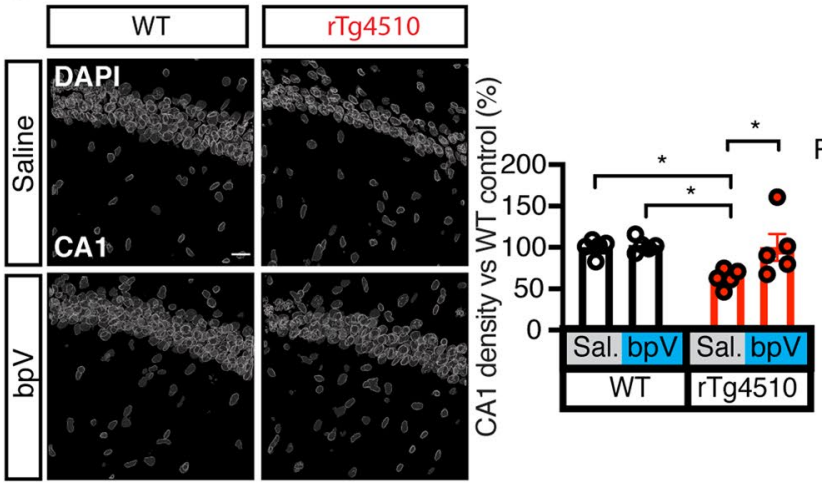

b

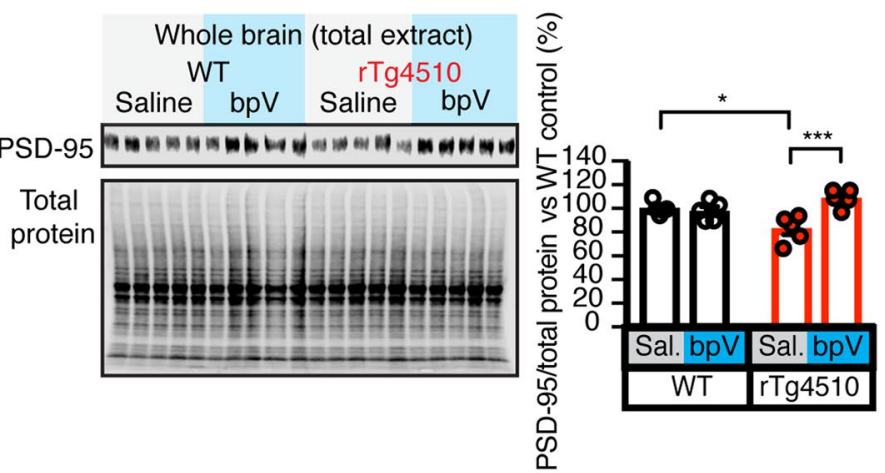

c

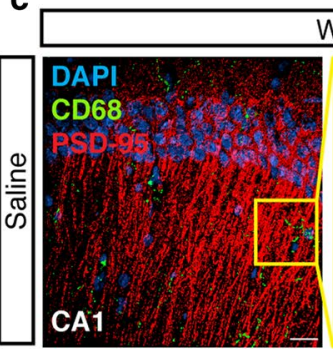

WT
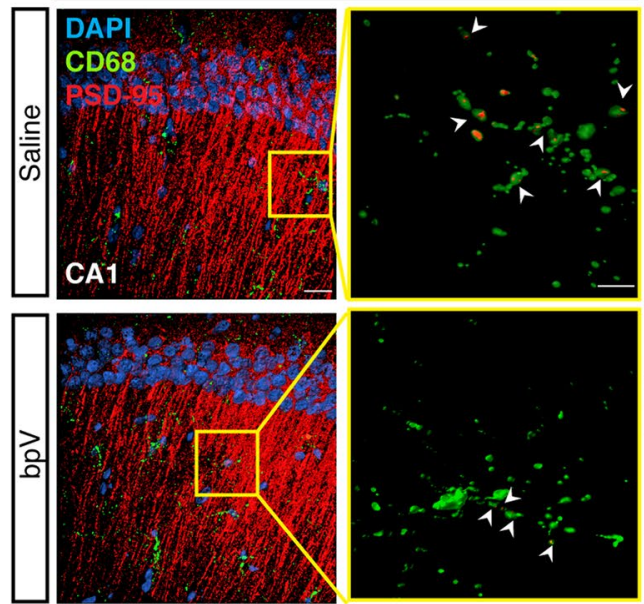

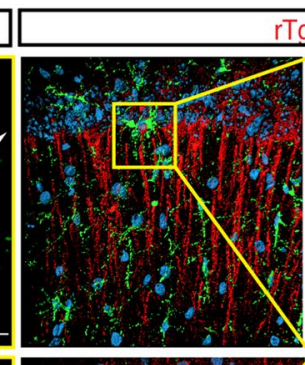

rTg4510

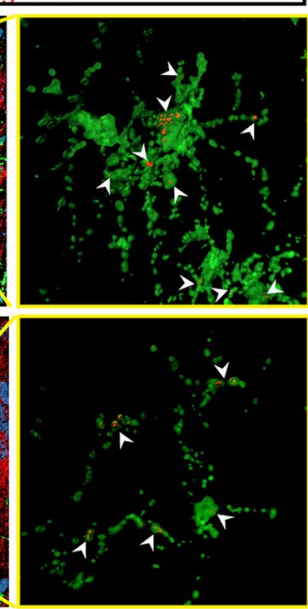

d
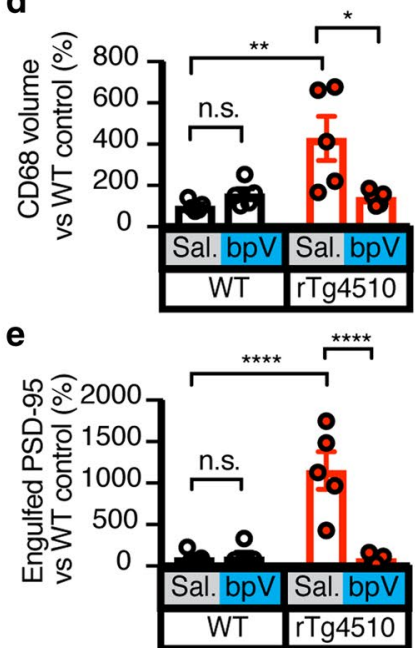

Fig. 7 PTEN inhibition prevents microglia mediated cell and synapse loss in rTg4510 mice. a Surface rendering of DAPI from all groups, showing a rescue in cellular density of the cellular layer of the CA1 region of the hippocampus following chronic PTEN inhibition. b Representative western blots and quantification for PSD-95 and total protein in brain lysates from saline- or bpV-treated rTg4510 and WT mice.), revealing increased PSD-95 levels in bpV-compared to saline-treated rTg4510 mice. c 3D renderings of PSD-95 (red), CD68 (green) and DAPI (blue) in the hippocampus of saline- or
bpV-treated rTg4510 and WT mice; arrowheads indicate engulfment. Scale bar in composite images: $20 \mu \mathrm{m}$; in zoomed-in images: $5 \mu \mathrm{m}$. d Quantification of CD68 volume, indicating that there is significantly less CD68 in rTg4510 mice treated with the PTEN inhibitor bpV. e Quantification of PSD-95 engulfed by microglia indicates that the rescue of PSD-95 loss in the bpV-treated group is due to a decrease in microglial engulfment. Data presented as mean $\pm \mathrm{SEM},{ }^{*} p<0.05$, $* * p<0.01, * * * p<0.001, * * * * p<0.0001 ; \mathbf{a}, \mathbf{b}, \mathbf{d}$, and e two-way ANOVA with Tukey's multiple comparison test time pathological Tau can, independent of $\mathrm{A} \beta$, promote microglia- and complement-mediated synapse loss [5, 10, $32,65]$. Our data are in agreement with these studies by revealing that synapse loss is, at least in part, mediated by microglia. We propose a process by which PTEN has a role in microglial uptake of neuronal structures in the presence of pathological Tau phosphorylation. In support, we preserved levels of PSD-95 in rTg4510 mice after chronic treatment with the PTEN inhibitor $b p \mathrm{~V}$ initiated prior to the occurrence of synapse loss. As the complement pathway functions in development and tauopathies to regulate synapse numbers $[10,18,53,54]$, PTEN may function similarly in tauopathy as it also regulates synapse numbers during development [29, 40, 64].

Recent evidence shows that physiological Tau restricts PTEN's activity, and that PTEN activity could increase as a result of a loss of function of Tau due to its aggregation [33]. In support of this notion, Tau has been shown to interact with other phosphatases, such as protein phosphatase $2 \mathrm{~A}$, through its proline-rich domain, which is also recognized by Fyn [51]. During the revision of our manuscript, a study has been published which shows that Tau indeed interacts with PTEN via Tau's proline-rich domain [57]. As diseaserelevant phosphorylation or FTLD mutations of Tau can increase the association with Fyn $[3,31]$, these pathological 


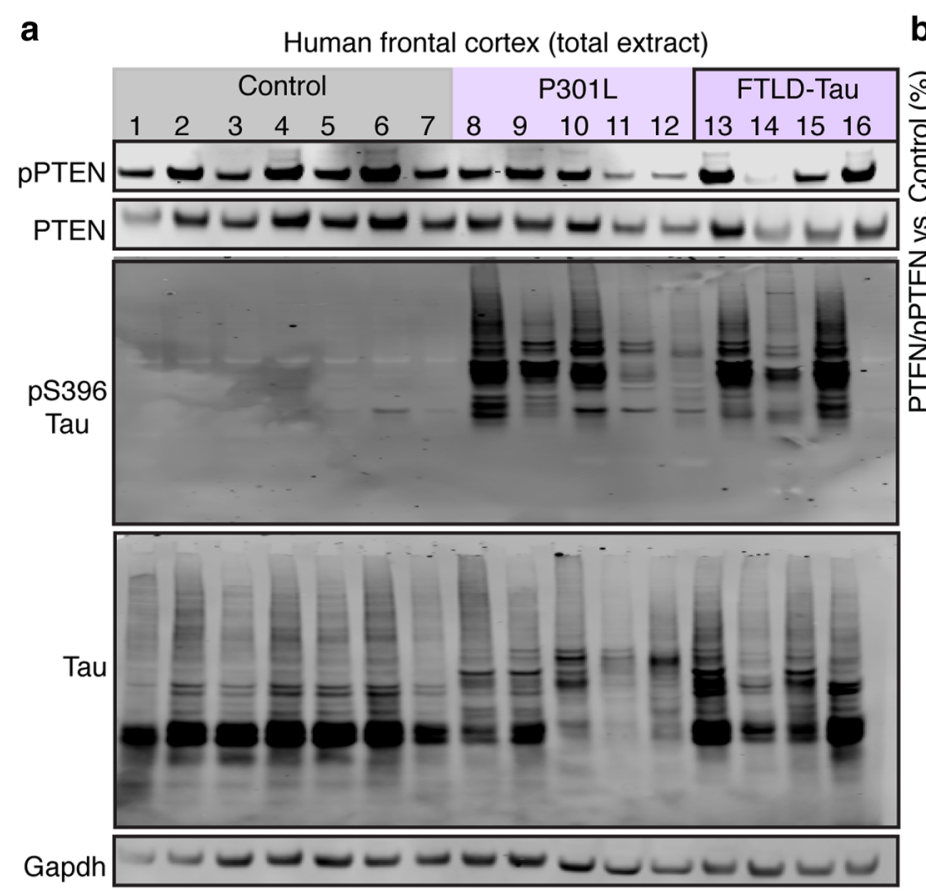

b $\quad$ c
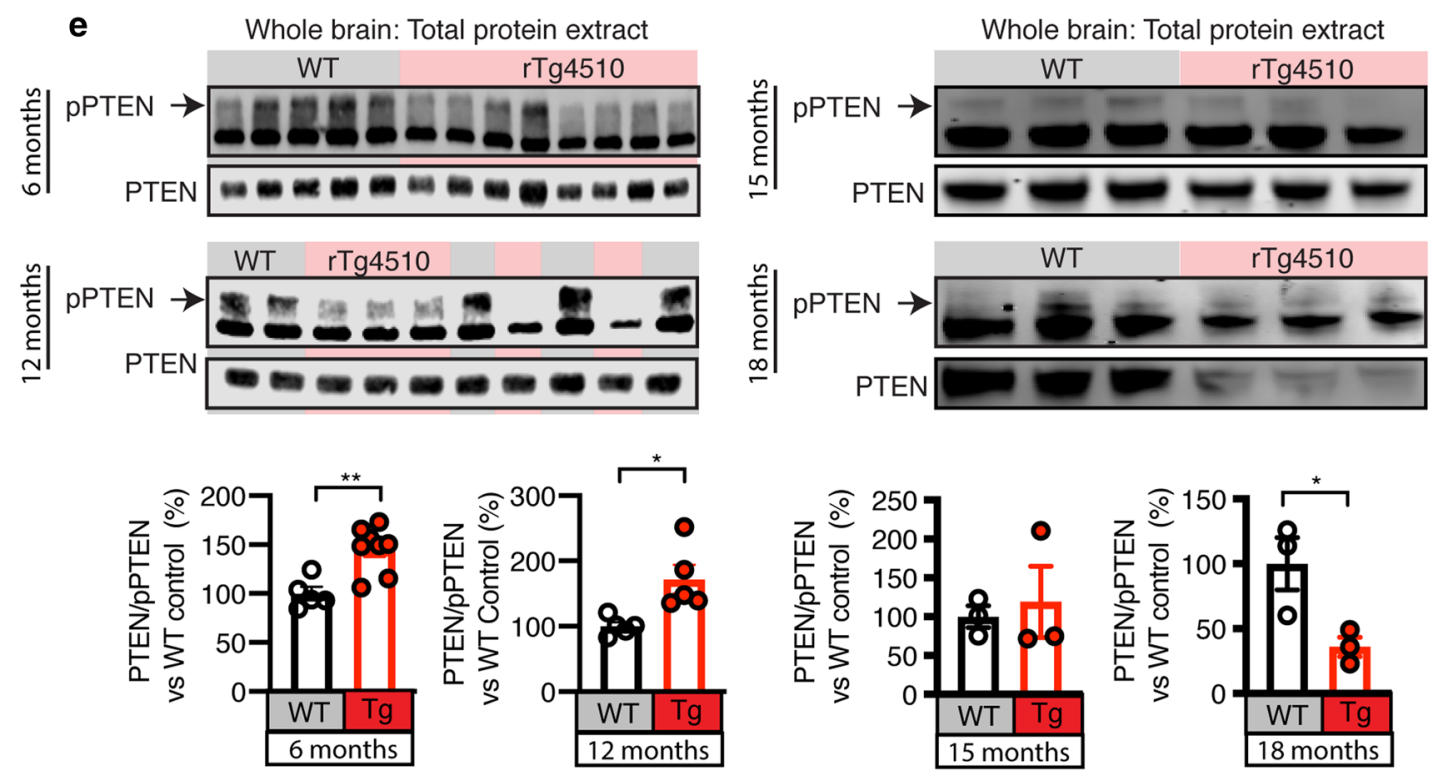

Fig. 8 PTEN activation negatively correlates with age in human FTLD-Tau patients. a Representative western blots of total protein extracts from the frontal cortex of human P301L mutation carriers, sporadic FTLD-Tau patients and healthy controls for pPTEN, PTEN, pS396 Tau, total Tau and Gapdh. b Quantification of PTEN activation (PTEN/pPTEN) from a. c Quantification of PTEN levels relative to Gapdh from a. d Correlation between PTEN/pPTEN and age in healthy control and combined familial and sporadic FTLD-Tau patients, showing a negative relationship between age and PTEN activation in disease patients $\left(r=-0.7396,{ }^{*} p=0.0360\right)$ and a positive

correlation in healthy controls $(r=0.7022, p=0.0786)$. One outlier was identified in the FTLD-Tau group and removed from the analysis. e Representative western blots and quantification of inactive pPTEN and total PTEN in total protein lysates from whole brains of $6,12,15$, and 18 month-old WT and rTg4510 mice, showing that PTEN activation begins at 6 months of age, peaks between 12 and 15 months and is decreased at 18 months relative to WT controls. Data presented as mean \pm SEM, ${ }^{*} p<0.05, * * p<0.01 ; \mathbf{b}$, c one-way ANOVA with Tukey's multiple comparison test, d Pearson correlation, e unpaired $t$ tests 
changes may release PTEN from being restricted by Tau. We found that PTEN inhibition by $b p V$ neither affected levels nor phosphorylation of Tau, indicating that PTEN functions downstream of Tau in mediating cellular and synaptic loss.

Regarding PTEN's lipid phosphatase pathway, which has primarily been studied in $A \beta$ rather than Tau models, we found that phosphorylation of the pro-survival pathway component AKT, did not differ between groups. Previously, the PTEN lipid phosphatase pathway has been shown to be dysregulated in APP/PSEN1 mice, leading to cognitive impairment [28]. In APP/PSEN1 mice, PTEN-regulated cognitive impairment presents as increased synaptic long-term depression, which is ameliorated by inhibition of PTEN with VOOHpic, or the synthetic peptide PTEN-PDZ, which disrupts the binding of PTEN to PSD-95 [28]. It is well established that PTEN's lipid phosphatase activity is required for its function in synaptic long-term depression, which may mediate synaptic dysfunction $[1,24,28]$, however PTEN's ability to induce spine loss is dependent on its protein phosphatase ability [67]. This may indicate that PTEN functions through its protein phosphatase activity to induce synapse loss which is considered to be upstream of cell loss in tauopathy, and protein substrates of PTEN could serve as potential therapeutic targets.

Targets of PTEN's protein phosphatase activity that may function in the process of cell and synapse loss are FAK and insulin receptor substrate 1 (IRS1) [48, 59]. It has been shown in Tau knockout mice, that PTEN is activated, leading to neuronal insulin resistance through PTEN dephosphorylation of IRS1 [33]. Neuronal insulin resistance, which can occur in tauopathy, has been shown to lead to neuronal dysfunction and synapse loss [6]. We found that inhibition of PTEN by bpV resulted in increased phosphorylation of FAK, which functions in the formation of dendritic spines through Rho family GTPases, a class of signaling G proteins shown to be downregulated in tauopathy $[10,39]$.

Our results focus on neuronal mechanisms elicited by PTEN inhibition; however, it is conceivable that PTEN functions in other cell types of the brain, such as microglia, also contribute to disease progression. Neuronal loss in tauopathy mice is facilitated by microglia [47]. Under pathological conditions, microglia release pro-inflammatory compounds such as nitric oxide and tumor necrosis factor- $\alpha$ that have toxic effects on neurons and oligodendrocytes, effects that can be reduced by PTEN inhibition [62]. It has also been shown that deletion of neuronal PTEN is sufficient to induce de novo myelination [14], and that myelin degeneration contributes to age-related cognitive decline [61].

In the current study, we have demonstrated that PTEN is associated with the degenerative process of tauopathy, and we revealed that inhibition of PTEN can, at least in part, rescue this process. We provided evidence that increased PTEN activation occurs in mouse models of tauopathy, promoting synapse loss. These changes to PTEN occur together with an increased presence of apoptotic markers and synaptic elimination by microglia. Finally, we provided evidence for a role of PTEN in synapse loss by chronic pharmacological inhibition of PTEN with the PTPase inhibitor bpV which reduced microglial engulfment of synapses. Considering that PTEN is a tumor suppressor, we caution that PTEN may not be a viable therapeutic target itself, whereas neuron- or synapsespecific substrates of its protein phosphatase activity may turn out to be safer alternatives. Thus, the synthetic PTENPDZ peptide which disrupts the interaction of PTEN and PSD-95 may present a more suitable therapeutic option than inhibitors of PTEN's enzymatic activity [27, 28]. In conclusion, our study adds PTEN to a growing number of proteins whose activity has seemingly opposing roles in diseases such as cancer $[7,17]$ and Tau-driven neurodegeneration.

Acknowledgements The authors wish to thank Drs Rodrigo Medeiros, Alexandra Grubman, Peter Noakes and Rowan Tweedale for their critical review of the manuscript. We thank Tishila Palliyaguru, Linda Cumner and Trish Hitchcock for their excellent technical support. This research was supported by the Estate of Dr Clem Jones AO, the State Government of Queensland, the Federal Government of Australia (ACT900116), and by grants from the Australian Research Council (ARC DP160103812) to JG and National Health and Medical Research Council (GNT1147569) to JG and LGB. LGB is supported by the Peter Hilton Fellowship. JB is supported by the Alistar Rushworth PhD scholarship. Imaging work was performed in the Queensland Brain Institute's Advanced Microscopy Facility and generously supported by ARC LIEF LE130100078. Human tissue was kindly provided by the Massachusetts ADRC.

Author contributions Conceptualization: J.B., L.G.B., J.G.; Design and performance of experiments: J.B., Additional experimental work: R.E.B., H.T.E., and S.A.E.; Writing: J.B., L.G.B., J.G.; Data discussion and analysis: J.B., L.G.B., J.G., R.E.B., and B.T.H.; Funding L.G.B., and J.G.; Supervision: L.G.B. and J.G.

\section{Compliance with ethical standards}

Conflict of interest The authors declare no competing interests.

Contact for Reagent and Resource Sharing Requests for additional information can be directed to the Lead Contact, Dr. Jürgen Götz, E-mail: j.goetz@uq.edu.au.

Open Access This article is licensed under a Creative Commons Attribution 4.0 International License, which permits use, sharing, adaptation, distribution and reproduction in any medium or format, as long as you give appropriate credit to the original author(s) and the source, provide a link to the Creative Commons licence, and indicate if changes were made. The images or other third party material in this article are included in the article's Creative Commons licence, unless indicated otherwise in a credit line to the material. If material is not included in the article's Creative Commons licence and your intended use is not permitted by statutory regulation or exceeds the permitted use, you will need to obtain permission directly from the copyright holder. To view a copy of this licence, visit http://creativecommons.org/licenses/by/4.0/. 


\section{References}

1. Arendt KL, Royo M, Fernandez-Monreal M, Knafo S, Petrok CN, Martens JR et al (2010) PIP3 controls synaptic function by maintaining AMPA receptor clustering at the postsynaptic membrane. Nat Neurosci 13:36-44. https://doi.org/10.1038/nn.2462

2. Bhaskar K, Hobbs GA, Yen S-H, Lee G (2010) Tyrosine phosphorylation of tau accompanies disease progression in transgenic mouse models of tauopathy. Neuropathol Appl Neurobiol 36:462 477. https://doi.org/10.1111/j.1365-2990.2010.01103.x

3. Bhaskar K, Yen S-H, Lee G (2005) Disease-related modifications in tau affect the interaction between Fyn and Tau. J Biol Chem 280:35119-35125. https://doi.org/10.1074/jbc.M505895200

4. Bolduc D, Rahdar M, Tu-Sekine B, Sivakumaren SC, Raben D, Amzel LM et al (2013) Phosphorylation-mediated PTEN conformational closure and deactivation revealed with protein semisynthesis. Elife 2:e00691. https://doi.org/10.7554/eLife.00691

5. Brelstaff J, Tolkovsky AM, Ghetti B, Goedert M, Spillantini MG (2018) Living neurons with tau filaments aberrantly expose phosphatidylserine and are phagocytosed by microglia. Cell Rep. https ://doi.org/10.1016/j.celrep.2018.07.072

6. Chow HM, Shi M, Cheng A, Gao Y, Chen G, Song X et al.2019) Age-related hyperinsulinemia leads to insulin resistance in neurons and cell-cycle-induced senescence. Nat Neurosci 22:18061819. https://doi.org/10.1038/s41593-019-0505-1

7. Cully M, You H, Levine AJ, Mak TW (2006) Beyond PTEN mutations: the PI3K pathway as an integrator of multiple inputs during tumorigenesis. Nat Rev Cancer 6:184-192

8. D'Amelio M, Cavallucci V, Middei S, Marchetti C, Pacioni S, Ferri A et al (2011) Caspase-3 triggers early synaptic dysfunction in a mouse model of Alzheimer's disease. Nat Neurosci 14:69-76. https://doi.org/10.1038/nn.2709

9. Das R, Klymchenko AS, Duportail G, Mély Y (2008) Excited state proton transfer and solvent relaxation of a 3-hydroxyflavone probe in lipid bilayers. J Phys Chem B 112:11929-11935. https:// doi.org/10.1021/jp804956u

10. Dejanovic B, Huntley MA, De Mazière A, Meilandt WJ, Wu T, Srinivasan K et al (2018) Changes in the synaptic proteome in tauopathy and rescue of tau-induced synapse loss by $\mathrm{C} 1 \mathrm{q}$ antibodies. Neuron 100:1322-1336.e7. https://doi.org/10.1016/j.neuro n.2018.10.014

11. Demchenko AP, Mély Y, Duportail G, Klymchenko AS (2009) Monitoring biophysical properties of lipid membranes by environment-sensitive fluorescent probes. Biophys J 96:3461-3470. https://doi.org/10.1016/j.bpj.2009.02.012

12. Fuchs Y, Steller H (2011) Programmed cell death in animal development and disease. Cell 147:742-758. https://doi.org/10.1016/j. cell.2011.10.033

13. Gary DS, Mattson MP (2002) PTEN regulates Akt kinase activity in hippocampal neurons and increases their sensitivity to glutamate and apoptosis. NeuroMol Med 2:261-270. https://doi. org/10.1385/NMM:2:3:261

14. Goebbels S, Wieser GL, Pieper A, Spitzer S, Weege B, Yan K et al (2017) A neuronal PI(3,4,5)P 3-dependent program of oligodendrocyte precursor recruitment and myelination. Nat Neurosci 20:10-15. https://doi.org/10.1038/nn.4425

15. Guo T, Noble W, Hanger DP (2017) Roles of tau protein in health and disease. Acta Neuropathol 133:665-704. https://doi. org/10.1007/s00401-017-1707-9

16. Györffy BA, Kun J, Török G, Bulyáki É, Borhegyi Z, Gulyássy $P$ et al (2018) Local apoptotic-like mechanisms underlie complement-mediated synaptic pruning. Proc Natl Acad Sci USA 115:6303-6308. https://doi.org/10.1073/pnas.1722613115
17. Hollander MC, Blumenthal GM, Dennis PA (2011) PTEN loss in the continuum of common cancers, rare syndromes and mouse models. Nat Rev Cancer 11:289-301

18. Hong S, Beja-Glasser VF, Nfonoyim BM, Frouin A, Li S, Ramakrishnan $\mathrm{S}$ et al (2016) Complement and microglia mediate early synapse loss in Alzheimer mouse models. Science 80(352):712716. https://doi.org/10.1126/science.aad8373

19. Hoover BR, Reed MN, Su J, Penrod RD, Kotilinek LA, Grant MK et al (2010) Tau mislocalization to dendritic spines mediates synaptic dysfunction independently of neurodegeneration. Neuron 68:1067-1081. https://doi.org/10.1016/j.neuron.2010.11.030

20. Hope-Roberts M, Horobin RW, Wainwright M (2011) Identifying apoptotic cells with the 3-hydroxyflavone derivative F2N12S, a ratiometric fluorescent small molecule probe selective for plasma membranes: a possible general mechanism for selective uptake into apoptotic cells. Biotech Histochem 86:255-261. https://doi. org/10.3109/10520291003723426

21. Ittner LM, Fath T, Ke YD, Bi M, van Eersel J, Li KM et al (2008) Parkinsonism and impaired axonal transport in a mouse model of frontotemporal dementia. Proc Natl Acad Sci USA 105:1599716002. https://doi.org/10.1073/pnas.0808084105

22. Ittner LM, Ke YD, Delerue F, Bi M, Gladbach A, van Eersel J et al (2010) Dendritic function of tau mediates amyloid-beta toxicity in Alzheimer's disease mouse models. Cell 142:387-397. https:// doi.org/10.1016/j.cell.2010.06.036

23. Jung S, Aliberti J, Graemmel P, Sunshine MJ, Kreutzberg GW, Sher A et al (2000) Analysis of fractalkine receptor CX(3)CR1 function by targeted deletion and green fluorescent protein reporter gene insertion. Mol Cell Biol 20:4106-4114

24. Jurado S, Benoist M, Lario A, Knafo S, Petrok CN, Esteban JA (2010) PTEN is recruited to the postsynaptic terminal for NMDA receptor-dependent long-term depression. EMBO J 29:28272840. https://doi.org/10.1038/emboj.2010.160

25. Kilin V, Glushonkov O, Herdly L, Klymchenko A, Richert L, Mely Y (2015) Fluorescence lifetime imaging of membrane lipid order with a ratiometric fluorescent probe. Biophys J 108:25212531. https://doi.org/10.1016/j.bpj.2015.04.003

26. Kim YE, Chen J, Chan JR, Langen R (2010) Engineering a polarity-sensitive biosensor for time-lapse imaging of apoptotic processes and degeneration. Nat Methods 7:67-73. https://doi. org/10.1038/nmeth.1405

27. Knafo S, Esteban JA (2017) PTEN: local and global modulation of neuronal function in health and disease. Trends Neurosci 40:83-91

28. Knafo S, Sanchez-Puelles C, Palomer E, Delgado I, Draffin JE, Mingo J et al (2016) PTEN recruitment controls synaptic and cognitive function in Alzheimer's models. Nat Neurosci 19:443-453. https://doi.org/10.1038/nn.4225

29. Kwon CH, Luikart BW, Powell CM, Zhou J, Matheny SA, Zhang $\mathrm{W}$ et al (2006) Pten regulates neuronal arborization and social interaction in mice. Neuron 50:377-388. https://doi.org/10.1016/j. neuron.2006.03.023

30. Lee YR, Chen M, Pandolfi PP (2018) The functions and regulation of the PTEN tumour suppressor: new modes and prospects. Nat Rev Mol Cell Biol 19:547-562

31. Li C, Götz J (2017) Somatodendritic accumulation of Tau in Alzheimer's disease is promoted by Fyn-mediated local protein translation. EMBO J 36:3120-3138. https://doi.org/10.15252/ embj.201797724

32. Litvinchuk A, Wan YW, Swartzlander DB, Chen F, Cole A, Propson NE et al (2018) Complement C3aR inactivation attenuates tau pathology and reverses an immune network deregulated in tauopathy models and Alzheimer's disease. Neuron 100:1337-1353.e5. https://doi.org/10.1016/j.neuron.2018.10.031

33. Marciniak E, Leboucher A, Caron E, Ahmed T, Tailleux A, Dumont $\mathbf{J}$ et al (2017) Tau deletion promotes brain insulin 
resistance. J Exp Med 214:2257-2269. https://doi.org/10.1084/ jem.20161731

34. Martin SJ, Reutelingsperger CP, McGahon AJ, Rader JA, van Schie RC, LaFace DM et al (1995) Early redistribution of plasma membrane phosphatidylserine is a general feature of apoptosis regardless of the initiating stimulus: inhibition by overexpression of Bcl-2 and Abl. J Exp Med 182:1545-1556

35. Milnerwood AJ, Gladding CM, Pouladi MA, Kaufman AM, Hines RM, Boyd JD et al (2010) Early increase in extrasynaptic NMDA receptor signaling and expression contributes to phenotype onset in Huntington's disease mice. Neuron 65:178-190. https://doi. org/10.1016/j.neuron.2010.01.008

36. Miyamoto T, Stein L, Thomas R, Djukic B, Taneja P, Knox J et al (2017) Phosphorylation of tau at Y18, but not tau-fyn binding, is required for tau to modulate NMDA receptor-dependent excitotoxicity in primary neuronal culture. Mol Neurodegener 12:41. https://doi.org/10.1186/s13024-017-0176-x

37. Paidassi H, Tacnet-Delorme P, Garlatti V, Darnault C, Ghebrehiwet B, Gaboriaud C et al (2008) C1q binds phosphatidylserine and likely acts as a multiligand-bridging molecule in apoptotic cell recognition. J Immunol 180:2329-2338

38. Pandit R, Leinenga G, Götz J (2019) Repeated ultrasound treatment of tau transgenic mice clears neuronal tau by autophagy and improves behavioral functions. Theranostics 9:3754-3767. https ://doi.org/10.7150/thno.34388

39. Rico B, Beggs HE, Schahin-Reed D, Kimes N, Schmidt A, Reichardt LF (2004) Control of axonal branching and synapse formation by focal adhesion kinase. Nat Neurosci. https://doi.org/10.1038/ nn1317

40. Sánchez-Puelles C, Calleja-Felipe M, Ouro A, Bougamra G, Arroyo A, Diez I et al (2019) PTEN activity defines an axis for plasticity at cortico-amygdala synapses and influences social behavior. Cereb Cortex. https://doi.org/10.1093/cercor/bhz103

41. Santacruz K, Lewis J, Spires T, Paulson J, Kotilinek L, Ingelsson $M$ et al (2005) Tau suppression in a neurodegenerative mouse model improves memory function. Science 80(309):476-481. https://doi.org/10.1126/science.1113694

42. Schafer DP, Lehrman EK, Kautzman AG, Koyama R, Mardinly AR, Yamasaki R et al (2012) Microglia sculpt postnatal neural circuits in an activity and complement-dependent manner. Neuron 74:691-705. https://doi.org/10.1016/j.neuron.2012.03.026

43. Scheff SW, Price DA, Schmitt FA, DeKosky ST, Mufson EJ (2007) Synaptic alterations in CA1 in mild Alzheimer disease and mild cognitive impairment. Neurology 68:1501-1508. https ://doi.org/10.1212/01.wnl.0000260698.46517.8f

44. Schmid AC, Byrne RD, Vilar R, Woscholski R (2004) Bisperoxovanadium compounds are potent PTEN inhibitors. FEBS Lett 566:35-38. https://doi.org/10.1016/J.FEBSLET.2004.03.102

45. Sheng M, Erturk A (2014) Long-term depression: a cell biological view. Philos Trans R Soc Lond B 369:20130138. https://doi. org/10.1098/rstb.2013.0138

46. Sheng M, Sabatini BL, Sudhof TC (2012) Synapses and Alzheimer's disease. Cold Spring Harb Perspect Biol 4:a005777a005777. https://doi.org/10.1101/cshperspect.a005777

47. Shi Y, Manis M, Long J, Wang K, Sullivan PM, Remolina Serrano $\mathrm{J}$ et al (2019) Microglia drive APOE-dependent neurodegeneration in a tauopathy mouse model. J Exp Med 216:2546-2561. https://doi.org/10.1084/jem.20190980

48. Shi Y, Wang J, Chandarlapaty S, Cross J, Thompson C, Rosen N et al (2014) PTEN is a protein tyrosine phosphatase for IRS1. Nat Struct Mol Biol 21:522-527. https://doi.org/10.1038/nsmb.2828

49. Shynkar VV, Klymchenko AS, Kunzelmann C, Duportail G, Muller CD, Demchenko AP et al (2007) Fluorescent biomembrane probe for ratiometric detection of apoptosis. J Am Chem Soc 129:2187-2193. https://doi.org/10.1021/ja068008h
50. Sonoda Y, Mukai H, Matsuo K, Takahashi M, Ono Y, Maeda K et al (2010) Accumulation of tumor-suppressor PTEN in Alzheimer neurofibrillary tangles. Neurosci Lett 471:20-24. https://doi. org/10.1016/J.NEULET.2009.12.078

51. Sontag JM, Nunbhakdi-Craig V, White CL, Halpain S, Sontag E (2012) The protein phosphatase PP2A/B $\alpha$ binds to the microtubule-associated proteins Tau and MAP2 at a motif also recognized by the kinase Fyn: implications for tauopathies. J Biol Chem 287:14984-14993. https://doi.org/10.1074/jbc.M111.338681

52. Spires-Jones TL, Hyman BT (2014) The intersection of amyloid beta and tau at synapses in Alzheimer's disease. Neuron 82:756771. https://doi.org/10.1016/J.NEURON.2014.05.004

53. Stephan AH, Barres BA, Stevens B (2012) The complement system: an unexpected role in synaptic pruning during development and disease. Annu Rev Neurosci 35:369-389. https://doi. org/10.1146/annurev-neuro-061010-113810

54. Stevens B, Allen NJ, Vazquez LE, Howell GR, Christopherson KS, Nouri N et al (2007) The classical complement cascade mediates CNS synapse elimination. Cell 131:1164-1178. https://doi. org/10.1016/j.cell.2007.10.036

55. Sturchler-Pierrat C, Abramowski D, Duke M, Wiederhold KH, Mistl C, Rothacher S et al (1997) Two amyloid precursor protein transgenic mouse models with Alzheimer disease-like pathology. Proc Natl Acad Sci USA 94:13287-13292

56. Sudom A, Talreja S, Danao J, Bragg E, Kegel R, Min X et al (2018) Molecular basis for the loss-of-function effects of the Alzheimer's disease-associated $\mathrm{R} 47 \mathrm{H}$ variant of the immune receptor TREM2. J Biol Chem 293:12634-12646. https://doi.org/10.1074/ jbc.RA118.002352

57. Tai C, Chang C-W, Yu G-Q, Lopez I, Yu X, Wang X et al (2020) Tau reduction prevents key features of autism in mouse models. Neuron. https://doi.org/10.1016/j.neuron.2020.01.038

58. Tai H-C, Serrano-Pozo A, Hashimoto T, Frosch MP, Spires-Jones TL, Hyman BT (2012) The synaptic accumulation of hyperphosphorylated tau oligomers in Alzheimer disease is associated with dysfunction of the ubiquitin-proteasome system. Am J Pathol 181:1426-1435. https://doi.org/10.1016/j.ajpath.2012.06.033

59. Tamura M, Gu J, Matsumoto K, Aota S, Parsons R, Yamada KM (1998) Inhibition of cell migration, spreading, and focal adhesions by tumor suppressor PTEN. Science 280:1614-1617. https://doi. org/10.1126/science.280.5369.1614

60. Walker CL, Wu X, Liu N-K, Xu X-M (2019) Bisperoxovanadium mediates neuronal protection through inhibition of PTEN and activation of PI3K/AKT-mTOR signaling after traumatic spinal injuries. J Neurotrauma 36:2676-2687. https://doi.org/10.1089/ neu.2018.6294

61. Wang F, Ren S-Y, Chen J-F, Liu K, Li R-X, Li Z-F et al (2020) Myelin degeneration and diminished myelin renewal contribute to age-related deficits in memory. Nat Neurosci 2020:1-6. https ://doi.org/10.1038/s41593-020-0588-8

62. Wang G, Shi Y, Jiang X, Leak RK, Hu X, Wu Y et al (2015) HDAC inhibition prevents white matter injury by modulating microglia/macrophage polarization through the GSK3 $\beta / P T E N /$ Akt axis. Proc Natl Acad Sci USA 112:2853-2858. https://doi. org/10.1073/pnas.1501441112

63. Wang Y, Cella M, Mallinson K, Ulrich JD, Young KL, Robinette ML et al (2015) TREM2 lipid sensing sustains the microglial response in an Alzheimer's disease model. Cell 160:1061-1071. https://doi.org/10.1016/j.cell.2015.01.049

64. Wong FK, Bercsenyi K, Sreenivasan V, Portalés A, FernándezOtero M, Marín O (2018) Pyramidal cell regulation of interneuron survival sculpts cortical networks. Nature 557:668-673. https:// doi.org/10.1038/s41586-018-0139-6

65. Wu T, Dejanovic B, Gandham VD, Carano RAD, Sheng M, Hanson Correspondence JE (2019) Complement C3 is activated in human $\mathrm{AD}$ brain and is required for neurodegeneration in mouse 
models of amyloidosis and tauopathy. Cell Rep. https://doi. org/10.1016/j.celrep.2019.07.060

66. You D, Xin J, Volk A, Wei W, Schmidt R, Scurti G et al (2015) FAK mediates a compensatory survival signal parallel to PI3KAKT in PTEN-Null T-ALL cells. Cell Rep 10:2055-2068. https ://doi.org/10.1016/j.celrep.2015.02.056

67. Zhang XC, Piccini A, Myers MP, Van Aelst L, Tonks NK (2012) Functional analysis of the protein phosphatase activity of PTEN. Biochem J 444:457-464. https://doi.org/10.1042/BJ20120098
Publisher's Note Springer Nature remains neutral with regard to jurisdictional claims in published maps and institutional affiliations. 